\begin{abstract}
UNIVERSIDADE DE SÃO PAULO
FACULDADE DE ODONTOLOGIA DE RIBEIRÃO PRETO DEPARTAMENTO DE MATERIAIS DENTÁRIOS E PRÓTESE
\end{abstract}

\title{
EFEITO DO GLUCONATO DE CLOREXIDINA A 2\% EM GEL, USADO DURANTE O PREPARO INTRARRADICULAR, NA RETENÇÃO DE NÚCLEOS METÁLICOS FUNDIDOS
}

Ricardo Souza da Silva

Ribeirão Preto 

RICARDO SOUZA DA SILVA

\section{EFEITO DO GLUCONATO DE CLOREXIDINA A $2 \%$ EM GEL, USADO DURANTE O PREPARO INTRARRADICULAR, NA RETENÇÃO DE NÚCLEOS METÁLICOS FUNDIDOS}

Ribeirão Preto 


\title{
EFEITO DO GLUCONATO DE CLOREXIDINA A 2\% EM GEL, USADO DURANTE O PREPARO INTRARRADICULAR, NA RETENÇÃO DE NÚCLEOS METÁLICOS FUNDIDOS.
}

Tese apresentada à Faculdade de Odontologia de Ribeirão Preto, da Universidade de São Paulo, como parte dos requisitos para a obtenção do grau de Doutor em Odontologia (Área de Reabilitação Oral).

Orientadora: Profa. Dra. Rossana Pereira de Almeida Antunes.

\author{
Ribeirão Preto
}


Autorizo a reprodução e divulgação total ou parcial deste trabalho, por qualquer meio convencional ou eletrônico, para fins de estudo e pesquisa, desde que citada a fonte.

\section{FICHA CATALOGRÁFICA}

Silva, Ricardo Souza da

Efeito do gluconato de clorexidina a $2 \%$ em gel, usado durante o preparo intrarradicular, na retenção de núcleos metálicos fundidos. Ribeirão Preto, 2007.

57p.:il.; $210 \times 297 \mathrm{~mm}$

Tese de Doutorado, apresentada à Faculdade de Odontologia de Ribeirão Preto/USP - Área de concentração: Reabilitação Oral.

Orientadora: Antunes, Rossana Pereira de Almeida

1.Clorexidina em gel. 2. Núcleos metálicos fundidos. 3. Preparo intrarradicular 


\section{Candidato(a): $\quad$ Ricardo Souza da Silva}

Título da tese:

Efeito do gluconato de clorexidina a $2 \%$ em gel, usado durante o preparo intrarradicular, na retenção de núcleos metálicos fundidos.

A comissão Julgadora dos trabalhos de Defesa de tese de doutorado, em sessão pública realizada em considerou o candidato:

1) Presidente: Profa. Dra. Rossana Pereira de Almeida Antunes.

Professora Associada do Departamento de Materiais Dentários e Prótese da Faculdade de Odontologia de Ribeirão Preto - USP.

Assinatura:

2) Examinador: Prof. Dr. Caio Cezar Randi Ferraz.

Professor Associado do Departamento de Odontologia Restauradora da Faculdade de Odontologia de Piracicaba - UNICAMP.

Assinatura:

3) Examinador: Prof. Dr. Flávio Henrique Baggio Aguiar.

Professor Doutor do Departamento de Odontologia Restauradora da Faculdade de Odontologia de Piracicaba - UNICAMP. 
4) Examinadora: Profa. Dra. Renata Cristina Silveira Rodrigues Ferracioli. Professora Doutora do Departamento de Materiais Dentários e Prótese da Faculdade de Odontologia de Ribeirão Preto - USP.

Assinatura:

5) Examinador: Prof. Dr. Osvaldo Luiz Bezzon.

Professor Titular do Departamento de Materiais Dentários e Prótese da Faculdade de Odontologia de Ribeirão Preto - USP.

Assinatura:

6) Suplente:

Assinatura:

7) Suplente:

Assinatura: 


\section{Mensagem aos leitores}

Não basta viver, é preciso sentir-se vivo. Afinal, a felicidade não é uma mina de ouro, e sim as pepitas que encontramos no caminho. Caminho este que não leva a mina alguma. Seja feliz hoje.

Dedicatória

Aos meus pais, Rainel e Nazilda, que sempre me incentivaram e ensinaram a escolher entre o certo e o errado.

À minha irmã, Helaine, pela serenidade e pela alegria.

À minha noiva, Ana Carolina, que não me deixa esquecer que é preciso sonhar sempre. 


\section{Agradecimento especial}

À Profa. Dra. Rossana Pereira de Almeida Antunes, minha orientadora, que me acolheu, incentivou e dividiu derrotas e vitórias. 
Minha formação como pessoa, cirurgião-dentista e pesquisador, recebeu a valiosa colaboração direta ou indireta de parentes, amigos, professores, funcionários e colegas. A estes, que ainda não foram mencionados, desejo expressar minha gratidão:

Ao Prof. Dr. Caio Cezar Randi Ferraz pela sua amizade e valiosos ensinamentos e por suas sugestões na realização deste trabalho.

Ao Prof. Dr. Francisco Carlos Groppo, meu primeiro orientador de iniciação científica, pelo brilhantismo, amizade sincera e extrema dedicação.

À Profa. Dra. Giselle Maria Marchi, minha segunda orientadora de iniciação científica, e à Mônica Campos Serra, co-orientadora, pelos ensinamentos.

À Profa. Célia Marisa Rizzatti Barbosa, minha tutora no estágio da disciplina de prótese parcial removível, por tornar meu trabalho muito mais rápido e de melhor qualidade.

Ao Prof. Dr. Wilkens Aurélio Albuquerque e Silva, por estender à mão no momento em que se precisa.

Aos Professores Rubens Ferreira de Albuquerque Júnior e Alma Blásida Concepcion Elizaur Benitez Catirse, membros da banca examinadora de minha qualificação.

Aos Docentes da Faculdade de Odontologia de Ribeirão Preto pela formação acadêmico-científica e disponibilidade de recursos materiais e humanos.

Aos funcionários do Departamento de Materiais Dentários e prótese da FORP-USP, em especial o técnico Luiz Sérgio Soares pelos serviços essenciais de idealização e confecção das matrizes utilizadas neste estudo, e aos técnicos Ricardo de Souza Antunes e Edson Volta, pela valiosa ajuda nos ensaios deste trabalho. 
Ao Prof. Dr. Heitor Panzeri, coordenador do Laboratório Integrado de Pesquisa em Materiais, pela utilização deste para os ensaios de tração.

À CAPES pelo apoio financeiro, através de bolsa de doutorado.

Aos estagiários, mestrandos, doutorandos da FORP-USP pelo convívio destes seis anos. Em especial a Cássio de Barros Pontes, Fábio Vinícius Teche, Hilmo Falcão Filho, Natércia Soriani e Fábio Jacobovitz.

Aos mestrandos em reabilitação da turma de 2001, pela amizade e torcida.

Aos alunos de graduação, que tão bem me acolheram e entre os quais fiz muitos amigos.

A todos os meus familiares que estão sempre torcendo.

Aos membros da família Gargaro pelo carinho, acolhimento e incentivo.

Ao grande amigo e irmão Paulo Raphael Brino Mattus, pela força de espirito, perseverança e confiança nos dias melhores.

Ao grande amigo, Professor Nilton Vivacqua Gomes, pelo incentivo na busca pela excelência e por suas sugestões na realização deste trabalho.

À $40^{a}$ turma da FOP-UNICAMP, os quais nunca esquecerei e sempre terei saudades.

A todos aqueles, que mesmo não mencionados, contribuíram para a realização deste trabalho, muito obrigado! 


\section{RESUMO}




\section{RESUMO}

A recontaminação do sistema de canais radiculares durante os procedimentos de preparo do espaço para núcleos metálicos fundidos deve ser evitada, sob pena de falha do tratamento endodôntico. $\mathrm{O}$ uso de substâncias antimicrobianas durante o procedimento pode ser interessante. $\mathrm{O}$ objetivo deste estudo foi avaliar o efeito do uso do gluconato de clorexidina a $2 \%$ em gel ou soro fisiológico (grupo controle), em conjunto com brocas para o preparo intrarradicular, sobre a retenção de núcleos metálicos fundidos, cimentados com fosfato de zinco ou um cimento resinoso (Panavia F). Foram utilizados 40 pré-molares inferiores humanos hígidos. Estes dentes foram tratados endodonticamente e receberam preparos intrarradiculares de $10 \mathrm{~mm}$ de profundidade, com as brocas número 2 de um sistema de pinos pré-fabricados de fibra de carbono. Em conjunto com estas brocas foi utilizado soro fisiológico (grupos 1 e 2 - controle) ou o gluconato de clorexidina em gel a $2 \%$ (grupos 3 e 4). Os condutos foram moldados e foram obtidos padrões em resina acrílica autopolimerizável. Os dentes foram incluídos em resina epóxica e depois em resina acrílica autopolimerizável. Os padrões foram fundidos em liga de níquel-cromo e cimentados com fosfato de zinco (grupos 1 e 3 ) ou Panavia F (grupos 2 e 4). Os espécimes foram mantidos em $100 \%$ de umidade relativa por 72 horas e em seguida, os pinos foram submetidos a forças de tração até serem desalojados. Os dados obtidos foram submetidos à análise de variância. Os valores das médias obtidas, em Kgf, foram: G1 - 21,744; G2 - 17,484; G3 25,229 e G4 - 20,028. Não houve diferença estatisticamente significante entre os grupos $(\mathrm{p}<0,05)$. Um protocolo de limpeza e desinfecção, para o preparo do espaço para pinos, deve ser estabelecido e o gluconato de clorexidina em gel a $2 \%$ não afetou negativamente a retenção de núcleos metálicos fundidos neste estudo. Estes dados sugerem que esta seja uma boa substância para auxiliar no preparo do espaço para pino, porque apresenta características vantajosas para o procedimento como: baixa toxicidade, fácil manuseio, atividade antimicrobiana e ação residual. 
ABSTRACT 


\begin{abstract}
Recontamination of the root canal during post space preparation must be avoided, under penalty of endodontic treatment failure. The use of antimicrobial substances in these procedures should be of interest. The aim of this study was to evaluate the retention of cast posts and cores luted with zinc phosphate cement and a resin cement (Panavia F), when burs and the $2 \%$ chlorhexidine gluconate in gel and saline were used for post space preparation. Forty sound human inferior premolars were used in this study. These teeth were treated endodontically, and had a $10 \mathrm{~mm}$ length post space preparation with the number 2 burs of a carbon fiber post system. In adjunction with this burs saline (G1 and G2 - control) and 2\% chlorhexidine gluconate in gel (G3 and G4) were used. Impressions were taken of the canals with acrylic resin. The teeth were included into epoxy resin and then into self-cure acrylic resin. The patterns were cast in niquel-cromium alloy then luted with zinc phosphate cement (groups 1 and 3) or Panavia F (groups 2 and 4). Specimens were stored in $100 \%$ of relative humidity for 72 hours. Then, the posts were dislodged by traction forces. The recorded data was submitted to ANOVA. The values of the averages obtained in Kgf were: G1 - 21.744; G2 - 17.484; G3 - 25.229 e G4 - 20.028. There was no statistical significant difference between the groups $(\mathrm{p}<0.05)$. Disinfection and cleaning protocol for the post space preparation must be established and the $2 \%$ chlorhexidine gluconate in gel did not affect negatively the retention of the cast posts in this study. This data suggests that this is a good auxiliary substance in the post space preparation because it presents advantage features for the procedure as: low toxicity, easy handle, antimicrobial action and substantivity.
\end{abstract}




\section{SUMÁRIO}

1 Introdução 1

2 Revisão de literatura 4

3 Proposição 14

4 Material e Método 16

4.1 seleção dos dentes $\quad 17$

4.2 identificação e distribuição dos dentes 17

4.3 tratamento endodôntico 17

4.4 preparo dos dentes $\quad 18$

4.5 moldagem e obtenção dos padrões $\quad 19$

4.6 inclusão dos dentes 20

4.7 fundição dos padrões $\quad 21$

4.8 cimentação dos N.M.F.s 22

4.9 ensaio de tração $\quad 24$

5 Resultados 26

6 Discussão 30

7 Conclusão $\quad 42$

8 Referências bibliográficas 44

9 Anexo 56 
1 INTRODUÇÃO 
$\underline{\text { Introdução }}$

O papel das bactérias e de seus subprodutos no início e perpetuação das doenças pulpares e periapicais está bem estabelecido (COHEN; BURNS, 2002). Portanto, o controle microbiano por meio de procedimentos biomecânicos é muito importante na efetividade dos tratamentos que envolvam os canais radiculares (FERRAZ et al., 2001).

Dentes que perderam demasiada estrutura coronária, por vezes, precisam receber tratamento endodôntico e retentores intrarradiculares para restauração com coroas protéticas (SHILLINGBURG et al., 1998).

Uma das causas de falhas endodônticas é a infiltração coronária de bactérias, por meio da saliva, reinfectando o sistema de canais radiculares (HELING et al., 2002). Sendo assim, seria interessante o uso de substâncias antimicrobianas, no controle da infecção, durante o preparo do conduto radicular para receber pinos préfabricados ou núcleos metálicos fundidos (N.M.F.).

Os N.M.F. são a opção de retentor intrarradicular mais difundida e utilizada (ERTUGRUL; ISMAIL, 2005; MEZZOMO et al., 2006b; NAUMANN et al., 2006). São confeccionados em ligas nobres, como o ouro tipo III e IV, ou em ligas alternativas como o cobre-alumínio e o níquel-cromo. É executado um preparo do canal radicular, com brocas de Gattes-Glidden, Largo ou Peeso, removendo gutapercha, cimento endodôntico e dentina. Desse modo, cria-se um espaço que é moldado, para que seja confeccionado um retentor fundido com adaptação precisa às paredes do conduto.

A retenção de N.M.F.s depende de fatores como comprimento do pino, diâmetro, forma anatômica e características da superfície (STANDLEE et al., 1978). Durante o preparo do espaço para N.M.F. toda a guta-percha e cimento endodôntico do canal radicular, no comprimento selecionado, devem ser removidos e as paredes radiculares devem estar limpas, o que possibilita que os procedimentos de moldagem e cimentação sejam executados com precisão.

No ato do preparo do espaço para N.M.F., a recontaminação do canal radicular deve ser evitada. Além de cuidados de isolamento, a utilização de uma substância antimicrobiana pode eliminar as bactérias que tenham se infiltrado no conduto através de restaurações provisórias. Uma substância antimicrobiana amplamente utilizada em odontologia atualmente, em função de reunir algumas 
$\underline{\text { Introdução }}$

propriedades vantajosas como biocompatibilidade e efeito residual, é a clorexidina (JEANSONNE; WHITE, 1994; WHITE et al., 1997; SIQUEIRA; UZEDA, 1997; KURUVILLA; KAMATH, 1998; KOMOROWSKI et al., 2000; LENET et al., 2000; FERRAZ et al., 2001; BASRANI et al., 2002; OLIVEIRA, 2002; VIANNA et al., 2004; DAMETTO et al., 2005; VIVACQUA-GOMES et al., 2005; ERCAN et al., 2006; VIANNA et al., 2006).

Sob a forma de gel na concentração de $2 \%$, o gluconato de clorexidina demonstrou grande capacidade de limpeza das paredes dentinárias, quando utilizado durante o tratamento endodôntico (FERRAZ et al., 2001).

Também foi observado aumento da força de adesão de pinos de fibra de carbono, fixados com cimento resinoso, quando foi utilizado o gluconato de clorexidina a $2 \%$ em gel, durante o preparo intrarradicular, em conjunto com as brocas indicadas, em relação ao grupo controle, onde foi usado soro fisiológico (SILVA et al., 2005).

De acordo com o exposto, o objetivo deste trabalho foi avaliar o efeito do uso do gluconato de clorexidina em gel a $2 \%$ ou soro fisiológico (grupo controle), em conjunto com brocas para o preparo intrarradicular, sobre a retenção de núcleos metálicos fundidos, fixados com dois agentes cimentantes. 


\section{REVISÃO DE LITERATURA}


Dentes extensamente cariados e com comprometimento pulpar necessitam de tratamento endodôntico, que consiste na remoção das restaurações antigas, do tecido cariado e da dentina radicular contaminada, além da eliminação das bactérias do conduto radicular e selamento do canal (COHEN; BURNS, 2002). Com a remoção desta estrutura dentinária e da polpa ocorrem modificações de ordem biomecânica nestes dentes (LOVDAHL; NICHOLLS, 1977; GLANTZ; NILNER， 1986; PLASMANS et al., 1988).

Acreditava-se que a desvitalização dos dentes diminuía significativamente a quantidade de água presente na dentina, e que este decréscimo pudesse prejudicar as propriedades biomecânicas dos dentes tratados endodonticamente (HELFER et.al., 1972). No entanto, trabalhos mais recentes demonstram que esta perda de umidade não é significativa (HUANG et.al., 1992; SEDGLEY et.al., 1992; PAPA et.al., 1994).

A mudança que parece ser de maior relevância é a estrutural, pela remoção de estrutura dental. No procedimento endodôntico, contribuem para a remoção de estrutura dental o acesso, limpeza e conformação do conduto radicular. Segundo REEH et al. (1989), a endodontia reduz a resistência dental em apenas 5\%, comparada a 60\% de decréscimo observado em procedimentos restauradores, como as restaurações mésioocluso-distais (M.O.D.). Dentes com necessidade de tratamento endodôntico freqüentemente apresentam cáries extensas comprometendo boa parte da estrutura coronária.

Diante disso, a perda coronária de estrutura dental parece ser um aspecto predominante na diminuição da resistência de dentes tratados endodonticamente. Como resultado, existe grande susceptibilidade à fratura, que pode comprometer o prognóstico do elemento dental em questão, dependendo da profundidade em que ela ocorre (GUTMANN, 1992; ASSIF; GORFIL, 1994). Como uma fratura radicular deve requerer um procedimento de aumento de coroa clínica ou extrusão ortodôntica, o que prejudica os tecidos de suporte e/ou a relação coroa-raiz, é vital que seja alcançada máxima resistência com procedimentos protético-restauradores (ROSENSTIEL, 2005).

Portanto, o reforço dos dentes tratados endodonticamente e extensamente destruídos, é necessário (GUTTMAN, 1992). Acreditava-se que os retentores 
intrarradiculares proveriam este reforço. Historicamente, existem alguns relatos de técnicas que objetivavam o reforço dos elementos dentais. No século XVIII, fauchard já utilizava pinos de madeira em canais radiculares para conseguir retenção de coroas. Com o passar do tempo a madeira expandiria no ambiente úmido aumentando a retenção do pino até que, infelizmente, a raiz fraturava verticalmente.

Outros esforços para desenvolver coroas retidas por pinos, no século XIX, foram limitados pela falha da terapia endodôntica daquela era. Muitas versões dos pinos do século XIX também utilizaram "pivots" de madeira, mas alguns dentistas relataram a utilização de pinos de metal preferidos por Black, onde uma coroa com faceta de porcelana era aparafusada no interior do canal radicular. Clark, em meados do século xix, desenvolveu uma variação, onde um tubo foi incluído para permitir a drenagem da área periapical ou do canal radicular. A coroa de Richmond foi introduzida em 1878 e consistia de um tubo rosqueado no canal com uma coroa aparafusada. Mais tarde esta coroa foi modificada e redesenhada eliminando o tubo rosqueado e criando um sistema de coroa e pino em peça única. Sua falta de praticidade as tornou impopulares. Este fato ficava evidente quando trajetórias de inserção divergentes do espaço para pino e do remanescente dental existiam, especialmente para retentores de próteses parciais fixas. Estas dificuldades levaram ao desenvolvimento de restaurações com retentor intrarradicular e coroa como entidades separadas, onde uma coroa artificial é cimentada sobre um retentor e a estrutura dental remanescente (MORGANO; BRACKETT, 1999).

Atualmente sabe-se que os retentores intrarradiculares não reforçam as raízes (GUZY; NICHOLLS, 1979). No entanto, são necessários para reter coroas protéticas, em casos onde não existe remanescente coronário suficiente para confecção de restaurações diretas. Os retentores intrarradiculares não só não reforçam as raízes, como alguns trabalhos mostram que podem causar concentração de estresse em determinadas áreas. Esta situação, aliada à perda de estrutura ocasionada pela cárie coronária, pela endodontia e em conjunto com o desgaste do preparo do espaço para pino, predispõe o elemento dental à fratura (LOVDAHL; NICHOLLS, 1977; HUNTER et al., 1989; GUTMANN, 1992).

O que confere reforço a estes elementos, após a cimentação de um retentor intrarradicular, são as coroas protéticas abraçando um colar cervical de $2 \mathrm{~mm}$, em 
direção apical, preparado em tecido dental sadio (FRANK, 1959; ROSEN, 1961; EISSMAN; RADKE, 1987; SORENSEN; ENGELMAN, 1990; ASSIF et al., 1993; TORBJÖRNER, et al., 1995; MORGANO, 1996; MORGANO; BRACKETT, 1999).

Os retentores intrarradiculares podem ser núcleos metálicos fundidos ou pinos pré-fabricados. Os pinos pré-fabricados são uma opção para restauração de dentes tratados endodonticamente, com economia de sessões clínicas. Segundo HELING et al. (2002), quanto mais rapidamente a restauração definitiva de um dente for confeccionada, após o tratamento endodôntico, maior a chance de sucesso. Podem ser encontrados em dois modos de retenção, em duas formas anatômicas, duas configurações de superfícies e vários materiais.

Considerando os modos de retenção os pinos podem ser ativos ou passivos (MORGANO; BRACKETT, 1999; ALBUQUERQUE, 2002). Pinos ativos são mais retentivos que passivos, porém podem gerar estresse dentro da raiz e ocasionar sua fratura. Isto porque são rosqueados em dentina enquanto os passivos são apenas justapostos e cimentados.

Quanto às formas anatômicas são paralelos ou cônicos, sendo que existem particularidades dependendo da marca comercial, como pinos paralelos com extremidade cônica. Pinos paralelos são mais retentivos que pinos cônicos. No entanto, para os pinos cônicos é confeccionado um preparo que segue a conformação do conduto radicular. Este fato diminui a remoção de estrutura dentinária evitando maior enfraquecimento da região apical. Já para pinos paralelos é criado um espaço que não corresponde à forma do canal radicular, o que pode predispor o elemento dental à fratura (STANDLEE et al., 1978, JOHNSON; SAKUMURA, 1978; RUEMPING et al., 1979).

Já as superfícies podem ser lisas ou serrilhadas. Os pinos serrilhados são mais retentivos que os lisos (STANDLEE et al., 1978, JOHNSON; SAKUMURA, 1978; RUEMPING et al., 1979).

Em relação ao material de que são confeccionados os pinos pré-fabricados podem ser metálicos e não-metálicos. Os pinos metálicos podem ser de aço inoxidável ou de titânio. Entre os não-metálicos estão os pinos cerâmicos, os pinos de fibra de vidro, quartzo e os pinos de fibra de carbono. Sobre os pinos cerâmicos, de fibra de vidro e quartzo existem poucos estudos, sendo que os pinos cerâmicos 
apresentam desvantagens consideráveis como alto custo, dureza elevada e conseqüente dificuldade para remoção do canal (ALBUQUERQUE, 2002). A adesão de cimentos resinosos aos pinos cerâmicos parece ser frágil (HEDLUND, 2003).

Como principais desvantagens dos pinos pré-fabricados podemos citar que a variedade de formas, marcas e materiais tornam difícil o seu domínio. Para cada sistema é necessária a compra de um kit específico, o que pode ser um empecilho em relação ao custo. Em geral, são indicados para cimentação com cimentos resinosos, que são mais onerosos e mais sensíveis à técnica do que o cimento de fosfato de zinco.

Os núcleos metálicos fundidos apresentam-se como a técnica clássica de retentor intrarradicular, conhecida e dominada pela maioria dos cirurgiões-dentistas (ERTUGRUL; ISMAIL, 2005; MEZZOMO et al., 2006b; NAUMANN et al., 2006). São necessárias, no mínimo, duas sessões clínicas para sua confecção e apresentam corrosão, já que em sua grande maioria são confeccionados em ligas básicas como o cobre-alumínio ou o níquel-cromo (PINKLEY; MORRIS, 1974). Apresentam como principal indicação situações de extensa perda coronária, principalmente ao nível gengival, onde o efeito férula fica comprometido (MEZZOMO et al., 2006b). Quando bem indicados e confeccionados podem apresentar taxas de falha, em torno de 1,56-6,5\% ao ano (BERGMAN et al., 1989; WEINE et al., 1991; HATZIKYRIAKOS et al., 1992; TORBJÖRNER et al., 1995). Quanto a este aspecto Heydecke e Peters (2002) concluem em seu trabalho de revisão que os núcleos metálicos fundidos tem índices de sucesso semelhantes aos pinos pré-fabricados.

Os critérios de confecção de retentores intrarradiculares, como comprimento, diâmetro e forma, devem ser seguidos rigorosamente a fim de proporcionar retenção e resistência adequada, minimizando os efeitos indesejados (STANDLEE et al., 1978).

a forma de resistência depende do correto preparo do remanescente coronário e do efeito de férula da coroa protética (SORENSEN; ENGELMAN, 1990). Estes autores observaram que quanto mais paredes preparadas em tecido dental sadio, paralelas ao longo eixo do dente, maior a resistência conferida. Mezzomo et al. (2006b), estudaram dentes que receberam núcleos metálicos fundidos e coroas totais 
fundidas. Os elementos que tiveram colar cervical de $2 \mathrm{~mm}$, preparado em tecido dental sadio, foram mais resistentes que aqueles sem este preparo.

Estudos in vitro têm demonstrado padrões de fratura desfavoráveis para dentes restaurados com núcleos metálicos fundidos e submetidos a forças compressivas, em relação à possibilidade de reparo (SIDOLI, ET AL., 1997; MAGALHÃES, 2000). Vários autores sugerem que os materiais usados para restaurar dentes tratados endodonticamente devem ter módulo de elasticidade semelhante ao da dentina (PURTON; PAYNE, 1996; PURTON; LOVE, 1996).

Dentes restaurados com pinos de fibra de carbono e submetidos a testes de compressão apresentaram melhores resultados em relação aos padrões de fratura e possibilidade de reparo quando comparados a dentes restaurados com núcleos metálicos fundidos (ISIDOR et al., 1996; SIDOLI et al., 1997; MARTINEZ-INSUA et al., 1998; MAGALHÃES, 2000) ou pinos pré-fabricados de aço inoxidável (ISIDOR et al., 1996; DEAN et al., 1998). Pinos de fibra de carbono têm módulo de elasticidade mais próximo ao da dentina que núcleos metálicos fundidos (18 a 21mpa) (PURTON; PAYNE, 1996; PURTON; LOVE, 1996). Há indícios de que núcleos fundidos com ligas que tenham módulo de elasticidade mais próximo ao da dentina melhoram a resistência dos elementos restaurados (MEZZOMO et al., 2006a).

A forma de retenção depende dos seguintes fatores:

$\checkmark$ Comprimento do pino: há consenso de que o pino deve ter no mínimo o comprimento da coroa clínica a ser restaurada, observando-se a manutenção de um remanescente de 4 a $5 \mathrm{~mm}$ de guta-percha apical, garantindo o selamento desta região (ALFREDO et al., 2006). Quanto mais longo o pino maior a retenção (STANDLEE et al., 1978; GLANTZ; NILNER, 1986), portanto maior a dificuldade em removê-lo em casos de retratamento endodôntico. Além disso, um pino com comprimento adequado distribui melhor as forças no interior do canal radicular diminuindo a concentração de estresse (HOLMES et al., 1996).

$\checkmark$ Diâmetro do pino: tem efeito reduzido sobre a retenção. Sendo assim, o conduto deve ser preparado com um alargamento mínimo, evitando desgaste excessivo de paredes dentinárias e enfraquecimento da raiz (STANDLEE et al., 1978). 
$\checkmark$ Configuração de superfície: núcleos metálicos fundidos podem ser jateados com óxido de alumínio a fim de criar irregularidades e micro-retenções que aumentam a retenção proporcionada pelo cimento (ERTUGRUL; ISMAIL, 2005).

Cimento utilizado: existe dúvida se os cimentos resinosos podem oferecer melhor retenção a retentores intrarradiculares em relação ao cimento de fosfato de zinco. Alguns trabalhos com pinos pré-fabricados apontam para esta possibilidade (ASSIF; FERBER, 1982; GOLDMAN et al., 1984; CHAN et al., 1993; ELMOWAFY; MILENKOVIC, 1994; MENDOZA et al., 1997; UTTER et al., 1997; DUNCAN; PAMEIJER, 1998) enquanto outros apresentaram resultados conflitantes (MENDOZA; EAKLE, 1994) e ainda achados contrários (RADKE et al., 1988; COHEN et al., 1992; HABIB et al., 2002; ERTUGRUL; ISMAIL, 2005; ALFREDO et al., 2006). Segundo Mendoza e Eakle (1994), os cimentos resinosos podem aumentar a resistência à fratura de dentes tratados endodonticamente. Alguns estudos in vitro apontam para esta possibilidade, outros discordam (MEZZOMO et al., 2006a), porém faltam estudos clínicos para embasar qualquer das hipóteses (SAUPE et al., 1996; MENDOZA et al., 1997).

Algumas características do canal radicular e dos cimentos resinosos parecem desempenhar papel importante na interpretação destes resultados. Condições adversas do espaço intrarradicular como: a menor densidade de túbulos dentinários de cervical para apical, a dificuldade de acesso da luz para cimento de polimerização dual e o alto fator de configuração cavitário (fator $\mathrm{C}$ ), resultam em maiores dificuldades de obtenção de um preenchimento adesivo livre de falhas. Alguns autores afirmam que o estresse gerado na polimerização dos cimentos resinosos resulta em falhas na interface adesiva (MANOCCI et al., 2003; CALHEIROS et al., 2004; GORACCI et al., 2004). Nestas condições a contração de polimerização pode exceder a força de união à dentina radicular (TAY et al., 2005). A redução ou eliminação da quantidade de carga, nos cimentos resinosos em relação aos compósitos, necessária para o melhor escoamento do cimento, tende a aumentar a contração de polimerização (MAK et al., 2002). A contração volumétrica resultante da polimerização dos compósitos é da ordem de 1,5 a 5\% (FERRACANE, 2005).

Para confecção dos núcleos metálicos fundidos é feito um preparo intrarradicular com brocas de peeso, gattes-glidden ou largo removendo parte do 
material obturador e pequena quantidade de dentina radicular (DICKEY et al., 1982; CAMP; TODD, 1983; MADISON; ZAKARIASEN, 1984; SUCHINA; LUDINGTON, 1985).

O preparo da dentina intrarradicular com brocas resulta na formação de uma lama dentinária ou smear layer (GWINNETT, 1984) que é uma camada de aproximadamente $10 \mu \mathrm{m}$ de hidroxiapatita e colágeno desnaturado (EICK et al., 1970; PASHLEY, 1984). É possível ainda que contenha restos bacterianos e dentina cariada (BRÄNNSTRÖM, 1984).

Para que ocorra a formação de uma camada híbrida é necessária à remoção da smear layer, com exposição das fibras colágenas e da dentina peri e intertubular; e bom molhamento da rede de colágeno pelos adesivos (BRÄNNSTRÖM, 1984; GWINNETT, 1984; PANIGHI; G’SELL, 1992).

Durante o preparo do espaço para pino, as bactérias, por meio da saliva, podem recontaminar o sistema de canais radiculares. Já que a recontaminação dos canais radiculares após a endodontia é uma das principais causas de retratamento endodôntico (COHEN; BURNS, 2002), é de se esperar que cuidados de assepsia sejam tomados durante o preparo de espaço para pino. Heling et al. (2002), afirma que medicamentos utilizados na limpeza, desinfecção e irrigação dos canais radiculares, durante o tratamento endodôntico, podem ser usados para o mesmo fim durante o preparo do espaço para pino.

O gluconato de clorexidina é um agente antibacteriano de amplo espectro que apresenta baixa toxicidade. Tem sido usado como irrigante endodôntico (JEANSONNE; WHITE, 1994; WHITE et al., 1997; KURUVILLA; KAMATH, 1998; FERRAZ et al., 2001) e medicação intracanal (SIQUEIRA; UZEDA, 1997; KOMOROWSKI et al., 2000; LENET et al., 2000). Seu mecanismo de ação se dá pela adsorsão das moléculas de clorexidina pela parede celular do microorganismo causando fuga de componentes intracelulares. $\mathrm{Na}$ concentração de $2 \%$ tem efeito bactericida em função da precipitação ou coagulação do citoplasma provavelmente causada por ligações protéicas cruzadas (FERRAZ et al., 2001). Diferente de outras substâncias usadas como antimicrobianos em endodontia, as moléculas da clorexidina podem ser captadas pela dentina prevenindo colonização microbiana por algum tempo. Este efeito é conhecido como atividade antimicrobiana substantiva 
(AAS), substantividade ou efeito residual e sua duração depende do tempo de exposição da dentina à clorexidina (BASRANI et al., 2002). Quando usada como irrigante a clorexidina proporciona um efeito residual de até 72 horas (WHITE et al., 1997). Maiores períodos de exposição, como no caso da medicação intracanal por sete dias, resultam em prolongado efeito residual (KOMOROWSKI et al., 2000; LENET et al., 2000; BASRANI et al., 2002).

Recentemente foi introduzido o gluconato de clorexidina $2 \%$ em base de gel de natrosol (hidroxietil celulose) que é um agente solúvel em água, não iônico, inerte, muito utilizado como espessante em xampus, géis e sabões baseados em substâncias catiônicas (FERRAZ et al., 2001). Estes autores demonstraram, pela microscopia eletrônica de varredura, propriedades superiores de limpeza das paredes dentinárias dos canais radiculares, pelo gluconato de clorexidina $2 \%$ em gel, quando utilizado como irrigante no tratamento endodôntico, quando comparado a água destilada, ao hipoclorito de sódio à $5,25 \%(\mathrm{NaOCl})$ e à clorexidina à $2 \%$ na forma líquida.

Já Oliveira (2002), avaliando a limpeza dos canais radiculares, no retratamento endodôntico, observou que técnicas que utilizaram o gel de clorexidina, combinada com limas ou brocas, obtiveram melhores resultados em relação aos grupos onde foi utilizado o xilol.

Em função da limpeza das paredes radiculares proporcionada por esta substância durante o tratamento e retratamento endodôntico, talvez esta possa exercer efeitos positivos sobre a retenção de núcleos metálicos fundidos, se utilizada durante o preparo de espaço para pino. Como efeito benéfico adicional, age como antimicrobiano, caracterizando cuidado complementar durante o preparo do espaço para pinos.

Foi demonstrado aumento da força de adesão de pinos de fibra de carbono fixados com cimento resinoso quando foi utilizado o gluconato de clorexidina a $2 \%$ em gel, durante o preparo intrarradicular em conjunto com as brocas indicadas em relação ao grupo controle onde foi usado soro fisiológico (SILVA et al., 2005). Este aumento na força de adesão também foi observado para restaurações de resina composta onde os preparos foram previamente lavados com a clorexidina a $2 \%$ na forma líquida (PILO et al., 2001). 
Muitos trabalhos avaliaram a retenção de núcleos metálicos fundidos, com diferentes comprimentos e fixados com diferentes cimentos. No entanto não foram encontrados trabalhos que tenham utilizado a clorexidina, como auxiliar no preparo do espaço para núcleos metálicos fundidos.

Considerando todos os fatores expostos e que a utilização desta substância pode vir a constituir um protocolo de preparo intrarradicular, onde haveria um maior cuidado com a recontaminação do conduto, acredita-se que é importante avaliar o efeito da clorexidina gel sobre a retenção de núcleos metálicos fundidos, cimentados com fosfato de zinco ou um cimento resinoso. 
3 PROPOSIÇÃO 
O objetivo deste trabalho foi avaliar o efeito do uso do gluconato de clorexidina em gel a $2 \%$ ou soro fisiológico (grupo controle), em conjunto com brocas para o preparo intrarradicular, sobre a retenção núcleos metálicos fundidos, cimentados com Fosfato de Zinco ou um cimento resinoso (Panavia F). 
4 MATERIAL E MÉTODO 


\subsection{Seleção dos dentes}

Foram selecionados 40 pré-molares inferiores humanos* , unirradiculares, sem tratamento endodôntico prévio, com os ápices totalmente formados. Estes dentes não apresentavam grandes restaurações coronárias nem cáries extensas, que atingissem a porção radicular. Feita uma marcação $1 \mathrm{~mm}$ acima da porção mais coronária da junção cemento-esmalte, as porções radiculares eram medidas e aquelas que apresentassem comprimento entre 14 e $18 \mathrm{~mm}$ eram selecionadas. Dentes com grande achatamento mesio-distal ou curvaturas acentuadas foram excluídos. Foram feitas radiografias, no sentido vestíbulo-lingual e mesio-distal, para visualização dos canais radiculares. Dentes com mais de um canal, considerando todo o comprimento da raiz, foram excluídos. Os dentes foram limpos com curetas periodontais e mantidos em solução de cloreto de sódio 0,9\% (Laboratório Tayuyna, Nova Odessa, Brasil), sob refrigeração (HAYASHI et al., 2005).

\subsection{Identificação e distribuição dos dentes}

Após a limpeza dos elementos dentais estes foram identificados, na superfície externa de suas raízes, com os números de 1 a 40, com uma caneta de retroprojetor. Foi aplicado um esmalte de unhas incolor para proteger a identificação. Estes elementos foram distribuídos dentro de quatro grupos experimentais, sendo que, cada grupo recebeu um dos elementos do conjunto de quatro dentes da sequiência numérica. Sendo assim, o primeiro grupo recebeu os elementos 1, 5, 9, 13, 17, 21, 25, 29, 33 e 37 . Os demais grupos também obedeceram este critério.

\subsection{Tratamento endodôntico}

As coroas foram cortadas a $1 \mathrm{~mm}$ da porção mais coronária da junção cemento-esmalte. Com uma sonda exploradora foram removidos os remanescentes do teto da câmara pulpar. O comprimento de trabalho foi obtido visualizando uma lima \#15 tipo K (Malleifer instruments, Ballaigues, Suíça) ultrapassar o forame apical, recuando $1 \mathrm{~mm}$. A partir deste ponto a anatomização do canal radicular foi

\footnotetext{
* Aprovado pelo comitê de ética em pesquisa, processo número 2005.1.250.58.5
} 
obtida através das técnicas de crown-down de Gattes com recuo escalonado no sentido ápice-coroa. Foi utilizada a seqüência de brocas de Gates-Glidden \#6, \#5, \#4, \#3 e \#2 (Malleifer instruments, Ballaigues, Suíça) avançando 2mm para cada em direção ao ápice. Era realizada irrigação entre as trocas das brocas com solução de hipoclorito de sódio à $1 \%$ (Probem, Catanduva, Brasil). Realizou-se então o recuo escalonado de 1 em $1 \mathrm{~mm}$ para as limas \#15, \#20, \#25, \#30, \#35, \#40 e \#45 (Malleifer instruments, Ballaigues, Suíça) a partir do ápice dental. Também foi realizada irrigação entre as trocas das limas com solução de hipoclorito de sódio à $1 \%$ (Probem, Catanduva, Brasil). Foi realizada prova do cone com cones de gutapercha ML (Konne, Belo Horizonte, Brasil) e obtida uma radiografia. Quando necessário era feita nova instrumentação. Os dentes eram secos com pontas de papel absorvente (Dentsply, Petrópolis, Brasil) e obturados, pelas técnicas de compressão hidráulica e cone único, com cones de guta-percha ML. O cimento endodôntico utilizado foi um cimento resinoso à base de hidróxido de cálcio (Sealer26, Dentsply, Petrópolis, Brasil) proporcionado e espatulado de acordo com as recomendações do fabricante. Os dentes foram armazenados em $100 \%$ de umidade relativa por um período mínimo de 72 horas para permitir a completa presa do cimento.

\subsection{Preparo dos dentes}

O preparo dos condutos foi realizado em blocos de quatro corpos de prova, um de cada grupo. Após o preparo do último corpo de prova do bloco, correspondente ao grupo 4, iniciava-se um novo bloco adotando-se o mesmo critério.

Para remoção da guta-percha e preparo intrarradicular foram utilizadas as brocas \#2 do sistema de pinos C-Post (Bisco, Schamburg, E.U.A.). Para cada grupo $(n=10)$ foi utilizado um par de brocas (inicial e final) novas e diferente do grupo seguinte. Durante o preparo do espaço para pino foi adotado o seguinte protocolo:

\section{Grupo 1 e 2 - solução de cloreto de sódio 0,9\% (Laboratório Tayuyna, Nova Odessa, Brasil) - soro fisiológico.}

Inicialmente foi criado um reservatório, necessário ao grupo do gel, e também adotado neste grupo controle, para padronização. Foi realizado preparo dos $5 \mathrm{~mm}$ coronários com a broca inicial e irrigação com $0,5 \mathrm{ml}$ de soro fisiológico. Em seguida, preparo dos $10 \mathrm{~mm}$ coronários com a broca inicial e irrigação com $0,5 \mathrm{ml}$ de 
soro fisiológico. Para finalizar, preparo dos $10 \mathrm{~mm}$ coronários com a broca final e irrigação com 1,0 ml de soro fisiológico. Nesta etapa, já com o preparo pronto, foi feita uma prova clínica de um pino de fibra de carbono \#2 (C-Post, Bisco, Schamburg, E.U.A.) com um stop endodôntico, para averiguar seu correto assentamento. Comprovado o comprimento adequado, foi feita irrigação final com 3,0 $\mathrm{ml}$ de soro fisiológico. Se o comprimento de trabalho não fosse alcançado, a broca final era utilizada novamente nos $10 \mathrm{~mm}$ coronários, nova irrigação com $1 \mathrm{~mL}$ de soro fisiológico era feita e nova prova clínica, descontando-se o volume de irrigação do volume final $(5 \mathrm{ml})$. Todos os passos podem ser observados na figura 1 .
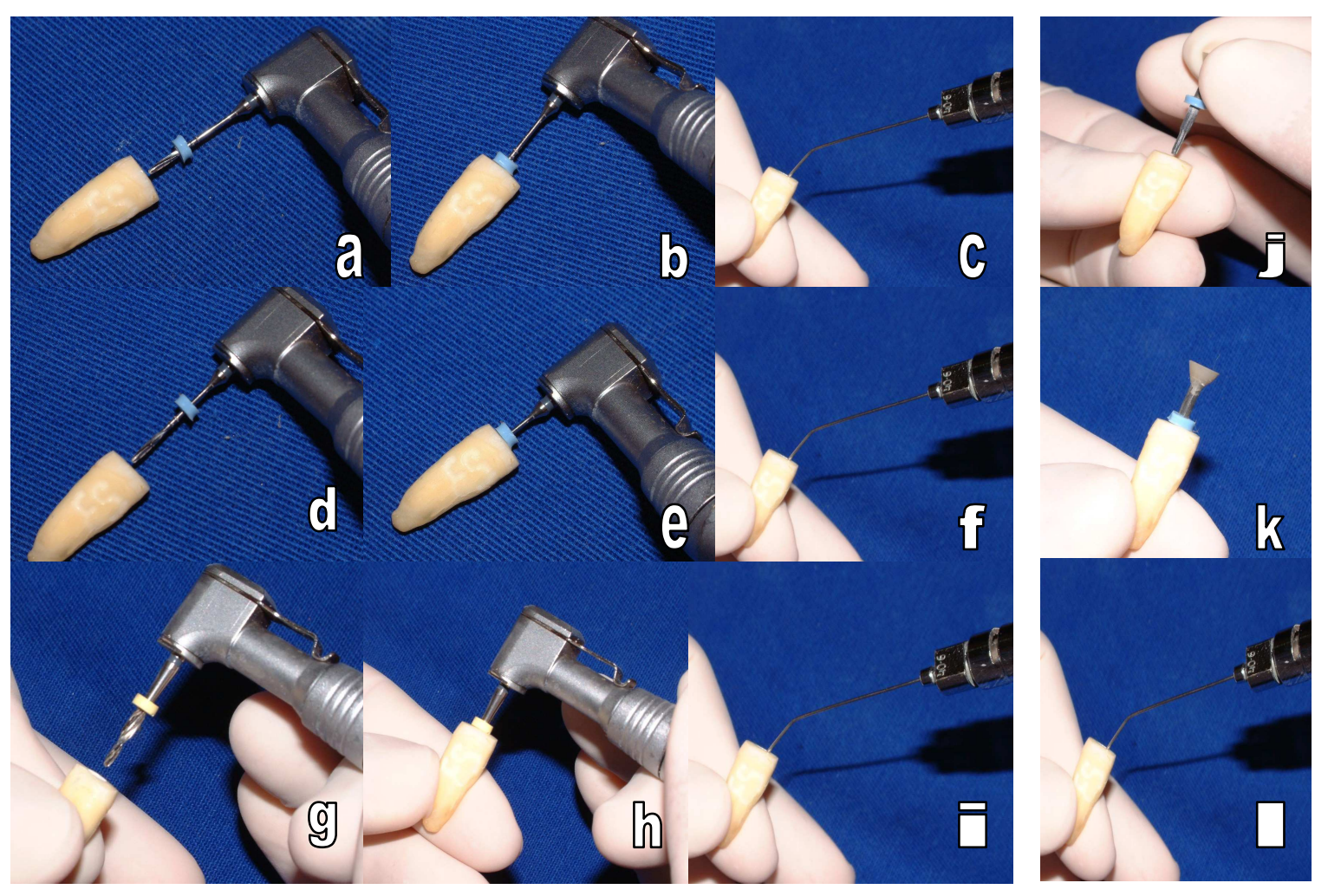

Figura 1. a,b,c) Preparo com a broca $1-0,5 \mathrm{~mm}+$ irrigação d,e,f) Preparo com a broca 1 10mm + irrigação g,h,i) Preparo com a broca 2 - 10mm + irrigação j,k,l) Prova clínica + irrigação.

\section{Grupo 3 e 4 - gluconato de clorexidina em gel 2\% - Endogel (Essencial} Pharma, Itapetininga, Brasil).

Neste grupo foi necessário criar um reservatório para conter o gel, dadas as propriedades do gel de clorexidina. Era realizado preparo dos $5 \mathrm{~mm}$ coronários com a broca inicial e irrigação com $0,5 \mathrm{ml}$ de clorexidina gel. Em seguida, preparo dos 10 
mm coronários com a broca inicial e irrigação com $0,5 \mathrm{ml}$ de clorexidina gel. Para finalizar, preparo dos $10 \mathrm{~mm}$ coronários com a broca final e irrigação com 1,0 ml de soro fisiológico. Neste momento, com o preparo pronto, foi realizada a prova clínica como descrito no grupo 1. Imperfeições no comprimento do preparo eram corrigidas como no grupo 1. Averiguado o preparo, foi feita irrigação final com 3,0 $\mathrm{ml}$ de soro fisiológico ou com o volume descontado, sempre totalizando $5 \mathrm{ml}$ como volume final. Os passos podem ser observados na figura 1, já que o esquema de preparo é o mesmo, variando somente as substâncias.

\subsection{Moldagem e obtenção dos padrões}

Antes da moldagem dos condutos, todos foram inspecionados visualmente e remanescentes de guta-percha visíveis foram removidos com o auxílio de uma sonda exploradora. Utilizando uma lima endodôntica recoberta com algodão, as paredes dos condutos foram lubrificadas com vaselina sólida, encontrada no kit da resina acrílica. Com o auxílio de pinos pré-fabricados plásticos Pinjet (Angelus, Londrina, Brasil) e resina acrílica autopolimerizável Duralay (Reliance Dental Mfg Co, IL, EUA), foram moldados os condutos dos elementos experimentais.

A resina acrílica era introduzida no interior dos condutos seguida da inserção de um pino plástico para a moldagem do conduto em toda a sua extensão (Fig. 2 - a, b). Com a porção radicular dos núcleos já moldada, passava-se à confecção da porção coronária. Para a adaptação em uma matriz de ensaio de tração, desenvolvida pela Oficina de Precisão do Departamento de Materiais Dentários e Prótese, os pinos receberam um núcleo de preenchimento de resina acrílica em forma de cone invertido. Para tanto, foi utilizada uma matriz de teflon, desenvolvida pela Oficina de Precisão do Departamento de Materiais Dentários e Prótese (Fig. 2 - c). A conformação cônica invertida justifica-se, apenas, para a adaptação do corpo de prova ao dispositivo desenvolvido para o ensaio de tração, de modo que não fossem induzidas tensões laterais durante o ensaio.

$O$ pino era inserido na matriz até que uma placa de vidro pudesse ser adaptada na superfície da mesma. Esta diferença de comprimento era ajustada através de um parafuso localizado na base da matriz (Figura 2 - c,d,e). Com o pino em posição a resina acrílica era inserida em incremento único. A placa de vidro era 
posicionada sobre a matriz para possibilitar a obtenção de uma superfície perpendicular ao longo eixo do pino. Com os padrões terminados, procedeu-se a inclusão dos dentes em resina e, em seguida, a fundição dos padrões.

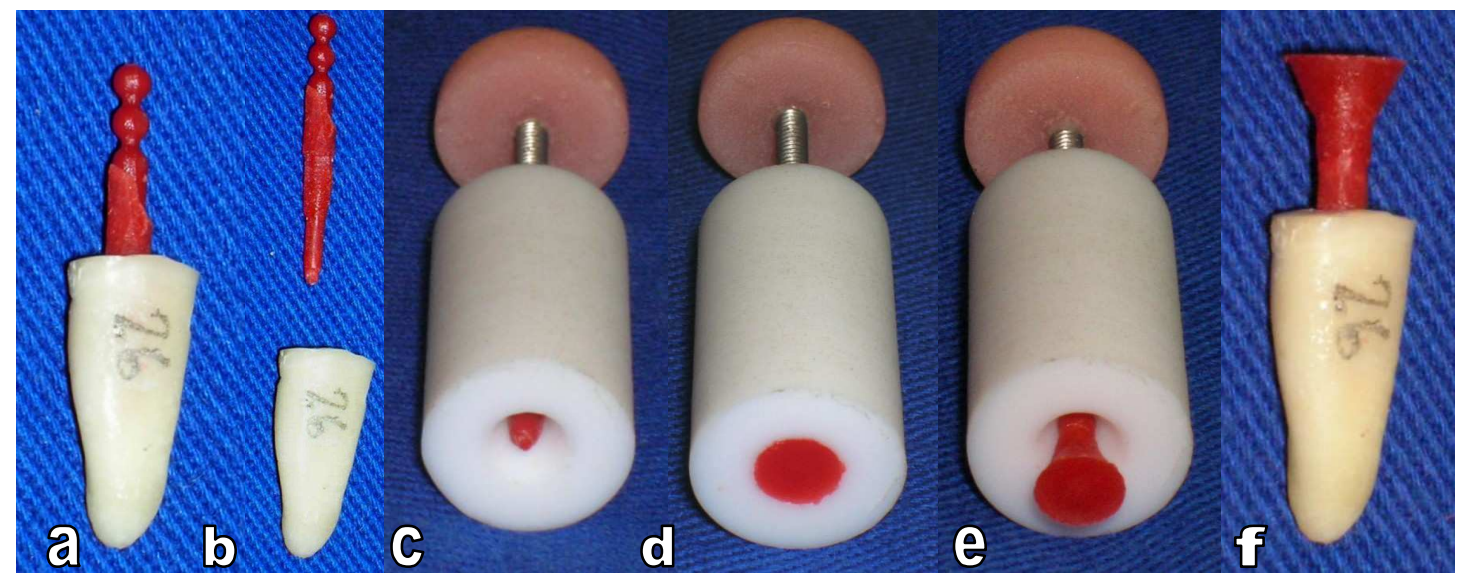

Figura 2. a,b) Moldagem da porção radicular c,d,e) confecção da porção coronária na forma de cone invertido com auxílio da matriz de teflon. f) porção coronária finalizada.

\subsection{Inclusão dos dentes}

Com os padrões de resina acrílica prontos foi possível adaptá-los no interior dos condutos e, com o auxílio de um paralelômetro (Bioart, São Carlos, Brasil), fazer a inclusão em resina acrílica autopolimerizável (Fig. 3). Desta maneira, o eixo de inserção dos dentes manteria paralelismo com o eixo de remoção no momento do ensaio de tração. Para evitar que a reação exotérmica da resina acrílica liberasse calor diretamente sobre os dentes, os mesmos foram pré-revestidos com resina epóxica Durepoxi (Alba, Boituva, Brasil) (Fig.3). Como os núcleos já se apresentavam cimentados nesta etapa, este revestimento tinha o intuito de proteger a interface dos agentes cimentantes com a dentina, a fim de evitar que o calor gerado pudesse influenciar o desempenho deste ou daquele cimento. Previamente foram criadas edentações nas raízes, com um disco de carborundum sob refrigeração, para retenção mecânica da resina epóxica (Fig. 3). 


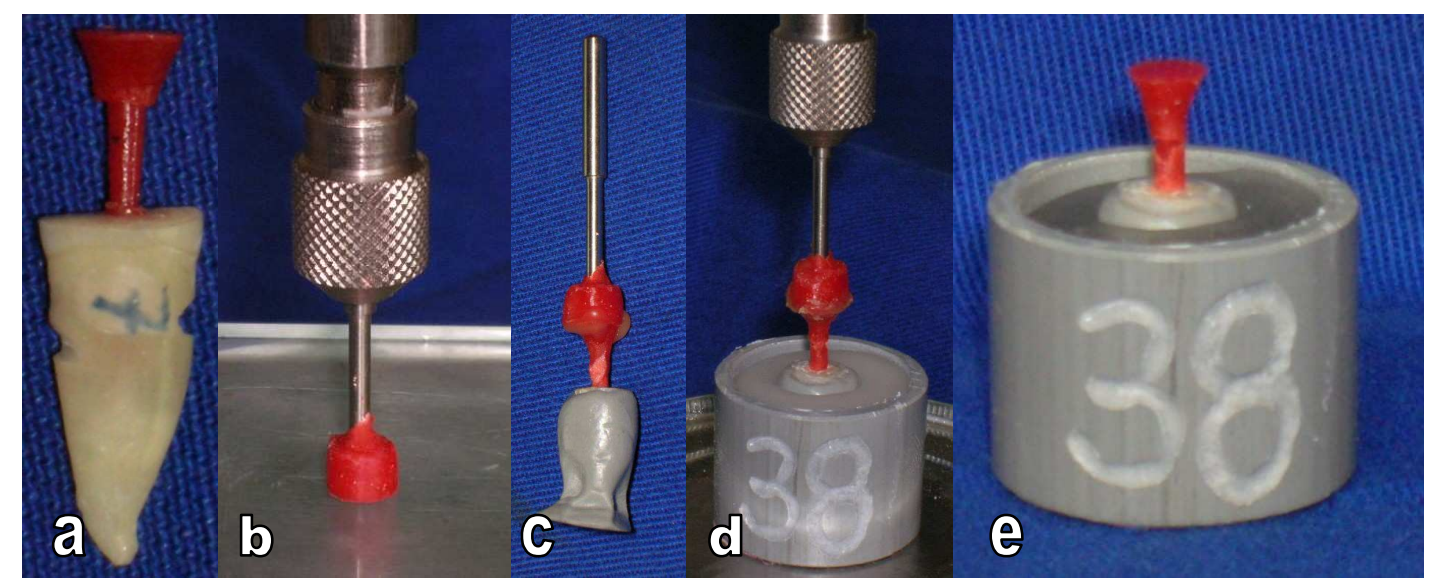

Figura 3. a) Retenções para a resina epóxica. b) Incremento de Duralay sobre placa de vidro. c) Dispositivo do paralelômetro preso com cera pegajosa ao padrão. d,e) Conjunto incluído em resina acrílica.

\subsection{Fundição dos padrões}

Os padrões foram incluídos em revestimento fosfatado Termocast (Polidental, São Paulo, Brasil), em um anel metálico de fundição. Para tanto foram ligados a condutos de alimentação de cera, sem câmara de compensação, e presos à base do anel. Todos foram identificados, para que pudessem voltar a seus respectivos corpos de prova. A liga utilizada na fundição foi a liga de níquel-cromo Verabond (Alba Dent., Cordélia, EUA).

Após a fundição, o revestimento foi eliminado e os núcleos foram cortados com discos de carborundum. Então, foi realizada a usinagem externa para remoção de nódulos e irregularidades. Foi feita uma prova nos condutos para observar a adaptação nos mesmos. Em caso de desadaptação, era feito o ajuste necessário. Caso contrário aquele núcleo estava apto a ser jateado. O jateamento foi feito com óxido

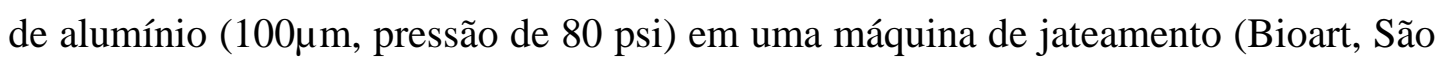
Carlos, Brasil). Dessa forma, os núcleos apresentavam-se prontos para a cimentação. 


\subsection{Cimentação dos N.M.F.s}

Foi feita prova clínica de todos os núcleos fundidos e marcações, com uma caneta de retroprojetor, para que fosse possível verificar que o núcleo, no momento da cimentação não ficasse fora de posição e após a cimentação, alcançasse o comprimento de trabalho (Figura $4 \mathrm{a}$ e $4 \mathrm{~d}$ ).

A cimentação dos núcleos foi executada em blocos de quatro corpos de prova, um de cada grupo. Após o preparo do último corpo de prova do bloco, correspondente ao grupo 4, iniciava-se um novo bloco adotando-se o mesmo critério.

Nesta etapa os núcleos dos grupos 1 e 3 foram cimentados com fosfato de zinco (DFL, Rio de Janeiro, Brasil) e os núcleos dos grupos 2 e 4 foram cimentados com Panavia F (Kuraray Medical Inc., Osaka, Japão).

Grupos 1 e 3 - Fosfato de Zinco

Com os núcleos já jateados, o cimento foi espatulado seguindo as recomendações do fabricante, aplicados sobre a porção radicular dos núcleos e estes cimentados nas raízes (Fig. 4 - b, c). Pressão digital foi exercida por 5 minutos em cada núcleo, para permitir a presa do cimento sem deslocamentos do núcleo. O excesso de cimento foi removido com uma sonda exploradora (Fig. 4 - d)

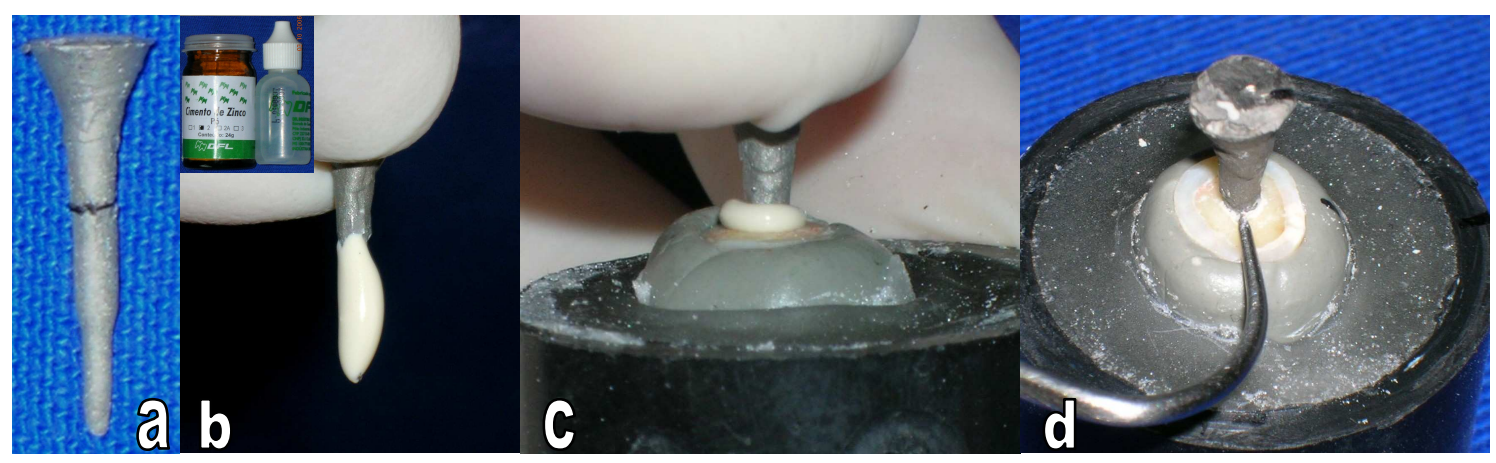

Figura 4. a) Procedimentos de cimentação com Fosfato de zinco.

Grupos 2 e 4 - Panavia F

As figuras 5 a e b mostram as marcações de referência. Os núcleos receberam uma camada de Alloy Primer (Kuraray Medical Inc., Osaka, Japão) e, após a secagem, uma segunda camada (Fig 5 - c). Os líquidos A e B do ED primer (Kuraray 
Medical Inc., Osaka, Japão) foram misturados e aplicados no interior do canal com um aplicador KG brusch (KG Sorensen, São Paulo, Brasil) (Fig 5 - d). Após 60 segundos, o excesso foi removido com o auxílio de pontas de papel absorvente (Dentsply, Petrópolis, Brasil). As pastas A e B do cimento foram dispensadas em doses iguais e espatuladas conforme as recomendações do fabricante. O cimento foi aplicado nos núcleos, que eram introduzidos nos canais radiculares, sob pressão digital, era feita a remoção do excesso de cimento, e a fotopolimerização por 40 segundos (Fig 5 - e, f, g, h). O fotopolimerizador utilizado foi o Ultralux (Dabi Atlante, Ribeirão Preto, Brasil) com intensidade de luz de $390 \mathrm{mw} / \mathrm{cm}^{2}$. Então, foi feita a aplicação do agente Oxyguard II (Kuraray Medical Inc., Osaka, Japão), espera de 40 segundos e remoção do agente (Fig 5 - i). Cada espécime foi mantido sob pressão digital por 5 minutos.

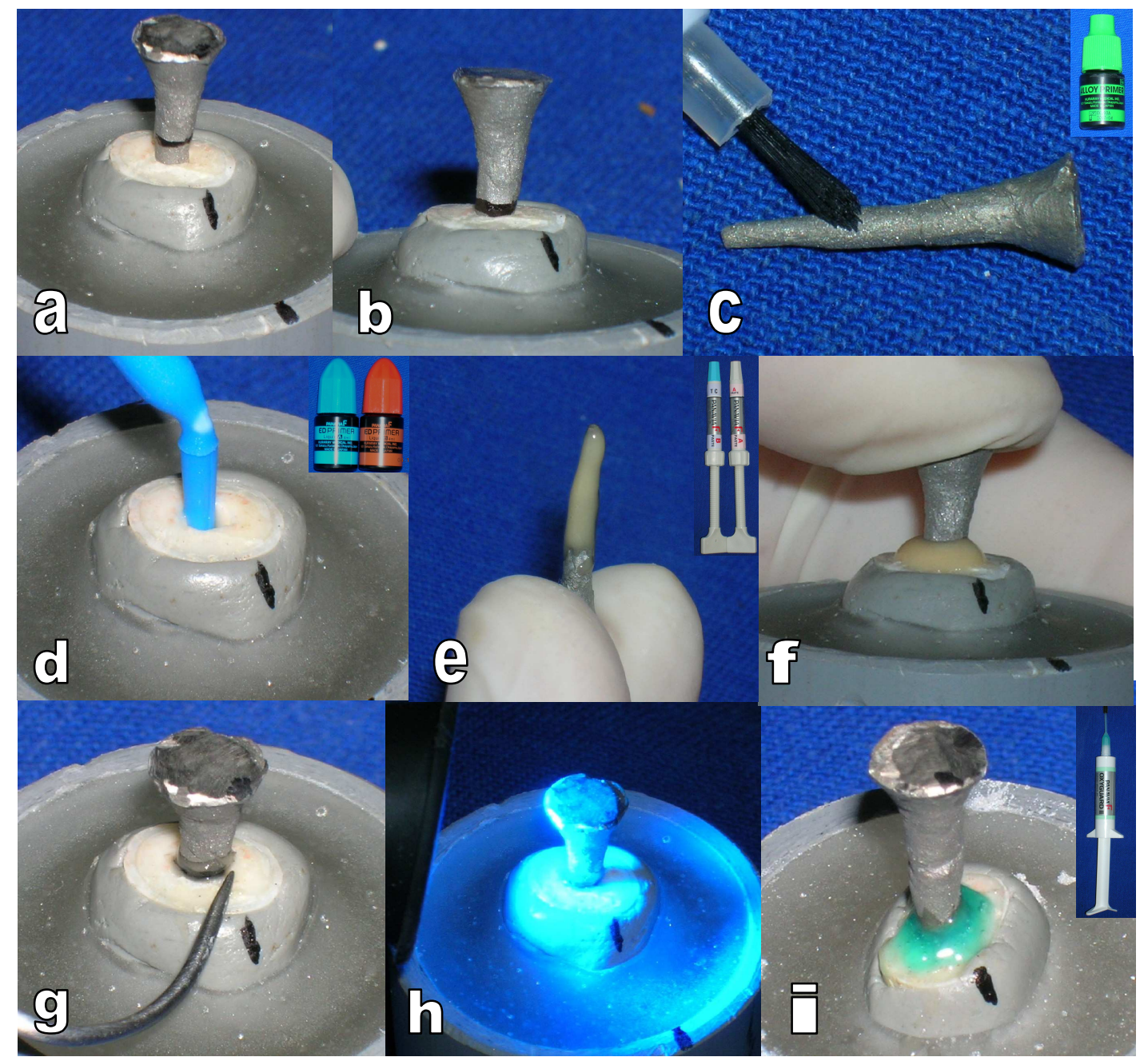

Figura 5. a) Procedimentos de cimentação com Panavia F. 


\subsection{Ensaio de tração}

Todos os elementos ficaram estocados em temperatura ambiente, por 72 horas, até o inicio do ensaio de tração

Os espécimes eram posicionados em uma máquina universal de ensaios modelo MEM 2000 (EMIC, São José dos Pinhais, Brasil), presos superiormente pelo cone invertido do núcleo à matriz já mencionada e inferiormente à base posicionadora em alumínio (Fig. 6). Os núcleos foram removidos a uma velocidade de $0.1 \mathrm{~mm} / \mathrm{minuto}$ com uma célula de carga de 50kgf. Os valores obtidos em kilograma-força (Kgf) foram tabulados e analisados estatisticamente, através da análise de variância (ANOVA).

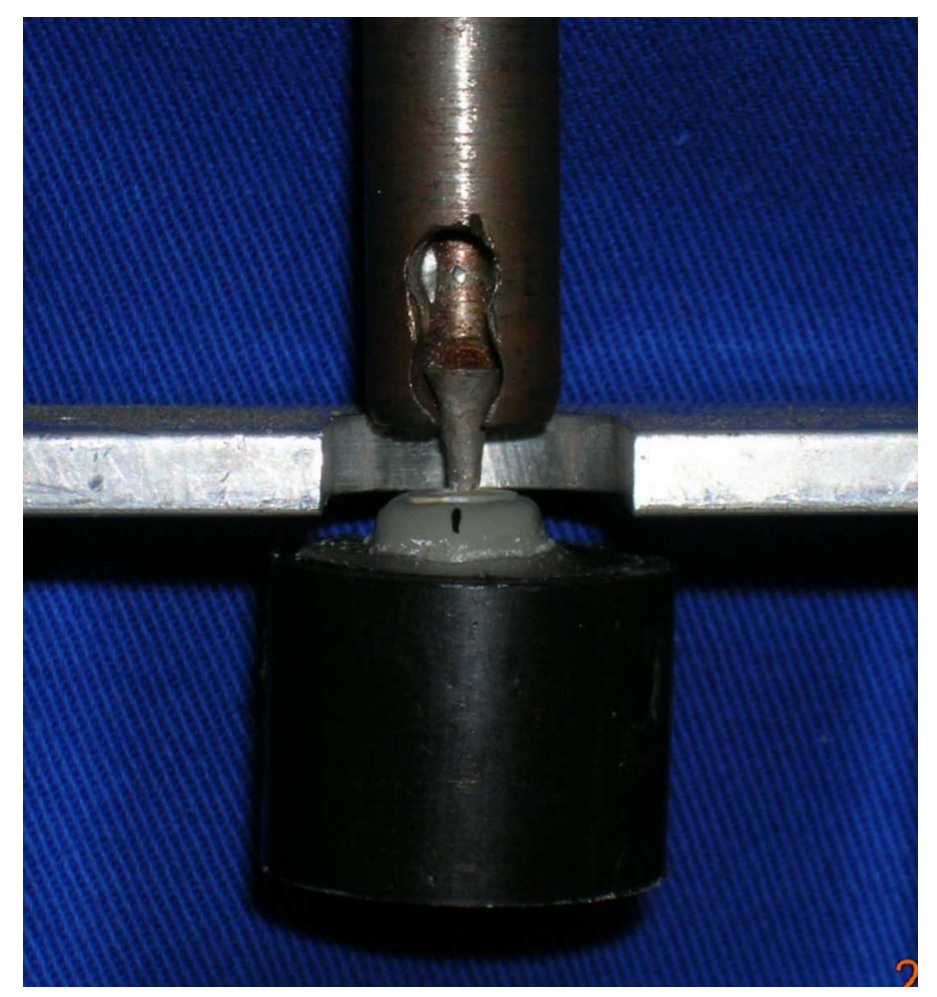

Figura 6. a) Procedimentos de cimentação com Panavia F. 


\section{RESULTADOS}




\section{Valores}

Os resultados do ensaio de tração são apresentados na tabela 1.

Tabela 1 - valores originais do ensaio de tração (kgf)

\begin{tabular}{ccccc}
\hline & Grupo 1 & Grupo 2 & Grupo 3 & Grupo 4 \\
n1 & 23,82 & 43,80 & 22,77 & 35,07 \\
n2 & 26,26 & 17,32 & 20,19 & 5,59 \\
n3 & 11,94 & 17,39 & 25,08 & 20,33 \\
n4 & 28,43 & 18,93 & 12,08 & 15,30 \\
n5 & 26,89 & 7,89 & 40,09 & 21,30 \\
n6 & 25,22 & 13,62 & 25,64 & 28,57 \\
n7 & 22,91 & 16,00 & 26,26 & 16,35 \\
n8 & 18,09 & 10,41 & 40,58 & 18,65 \\
n9 & 9,64 & 11,67 & 21,72 & 13,83 \\
n10 & 24,24 & 17,81 & 17,88 & 25,29 \\
\hline
\end{tabular}

\section{Análise estatística}

Para a análise estatística foi utilizado o programa estatístico do Professor Geraldo Maia Campos, GMC, disponível gratuitamente no endereço eletrônico www.forp.usp.br/restauradora/gmc/gmc.html.

Os testes estatísticos preliminares indicaram a normalidade e homogeneidade da amostra, portanto foram aplicados testes estatísticos paramétricos (Tabela 2 e 3).

Tabela 2 - Teste de aderência à curva normal

\begin{tabular}{|c|c|c|c|c|c|c|c|}
\hline \multicolumn{8}{|c|}{ Teste de aderência à curva normal: valores originais } \\
\hline \multicolumn{8}{|c|}{ Freqüências por intervalo de classe: } \\
\hline Intervalos de classe & M-3s & $\mathrm{M}-2 \mathrm{~s}$ & M-1s & Med. & $\mathrm{M}+1 \mathrm{~s}$ & $\mathrm{M}+2 \mathrm{~s}$ & $\mathrm{M}+3 \mathrm{~s}$ \\
\hline Curva normal & 0,44 & 5,40 & 24,20 & 39,89 & 24,20 & 5,40 & 0,44 \\
\hline Curva experimental & 0,00 & 5,00 & 22,50 & 50,00 & 12,50 & 7,50 & 2,50 \\
\hline \multicolumn{8}{|c|}{ Calculo do Qui-Quadrado } \\
\hline Graus de liberdade & & & 4 & \multirow{2}{*}{\multicolumn{4}{|c|}{$\begin{array}{c}\text { A distribuição amostral } \\
\text { testada é normal }\end{array}$}} \\
\hline Valor do Qui-quadra & & \multicolumn{2}{|c|}{9,18} & & & & \\
\hline Probabilidade de $\mathrm{H} 0$ & & \multicolumn{2}{|c|}{$5,66 \%$} & & & & \\
\hline
\end{tabular}


Tabela 3 - Teste de homogeneidade de Cochran

\begin{tabular}{lcc}
\hline \multicolumn{3}{l}{ Teste de homogeneidade de Cochran } \\
\hline Número de variâncias testadas : & 4 \\
Número de graus de liberdade : & 9 \\
Variância maior & $:$ & 98,6429 \\
Soma das variâncias & $:$ & 289,0014 \\
Valor calculado pelo teste $\quad:$ & 0,3413
\end{tabular}

O teste estatístico aplicado foi a análise de variância (ANOVA) (Tabela 4).

Tabela 4 - Valores obtidos na análise de variância.

\begin{tabular}{lccccc}
\hline \multicolumn{5}{c}{ Análise de variância: valores originais } & \\
Fonte de variação & Soma dos quadrados & G.L. & Quadrados médios & $F$ & Probabilidade (Ho) \\
Entre colunas (C) & 223,7750 & 1 & 223,7750 & 3,10 & $8,338 \%$ \\
Entre linhas (L) & 90,8719 & 1 & 90,8719 & 1,26 & $26,882 \%$ \\
Interação C x L & 2,2141 & 1 & 2,2141 & 0,03 & $14,379 \%$ \\
Resíduo & 2601,0103 & 36 & 72,2503 & & \\
Variação total & 2917,8711 & 39 & & & \\
& & & & & \\
\end{tabular}

Como o F calculado é menor que o F tabelado de 4,17 - 4,08 (intervalo v2 30-40, tabela distribuições F de Snedecor) em todas as situações, a análise de variância demonstrou que não houve diferença estatisticamente significante, ao nível de $5 \%$ de probabilidade, entre os grupos. 
Tabela 5 - Médias dos grupos experimentais

\begin{tabular}{lc}
\hline \multicolumn{1}{c}{ Grupo experimental } & Médias e desvio padrão (Kgf) \\
G3 - Clorexidina/Fosfato & $25,229 \pm 8,996 \mathrm{a}$ \\
G1 - Soro/Fosfato & $21,744 \pm 6,425 \mathrm{a}$ \\
G4 - Clorexidina/Panavia & $20,028 \pm 8,255 \mathrm{a}$ \\
G2 - Soro/Panavia & $17,484 \pm 9,932 \mathrm{a}$ \\
\hline
\end{tabular}

Letras semelhantes ao lado das médias indicam valores estatisticamente semelhantes. Valores entre parênteses representam o desvio-padrão $(\mathrm{p}<0,05)$.

Os valores da tabela 5 foram utilizados para a elaboração do gráfico da figura 6 .

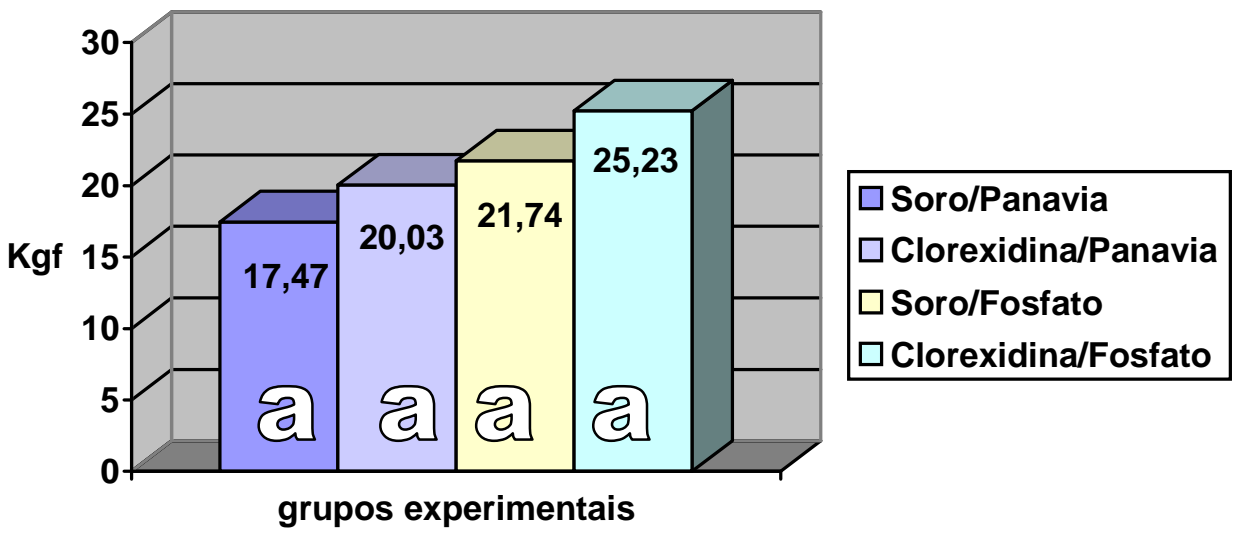

Figura 6. Gráfico representativo dos valores de retenção em Kgf. 
6 DISCUSSÃO 
Neste estudo foram utilizados segundos pré-molares inferiores humanos, que são dentes que raramente apresentam variações radicais de morfologia. Em apenas 2,5\% dos casos apresentam um segundo canal na região apical. Quando é considerada toda a extensão da raiz, em $12 \%$ dos casos possuem um segundo ou terceiro canal. Os pré-molares inferiores são dentes que possuem câmaras pulpares e canais radiculares medianamente ovalados e relativamente retos (BURNS; HERBRANSON, 2002).

Os estudos de retenção e força de adesão, com núcleos metálicos fundidos ou pinos pré-fabricados, utilizam dentes humanos. Newman et al., (2003), indicam a utilização destes dentes, considerando que são boa alternativa para simular a situação clínica de dentes tratados endodonticamente.

Os dentes empregados neste trabalho foram tratados endodonticamente seguindo um protocolo de preparo (DE DEUS, 1992). Serafino et al., (2004) demonstraram, através da microscopia eletrônica de varredura, que após o preparo do espaço para retentores intrarradiculares, as paredes do conduto ficam cobertas por smear layer, debris e remanescentes de guta-percha e cimento endodôntico. Por esse motivo, é importante que os canais sejam obturados para que os testes com pinos cimentados reproduzam mais fielmente a realidade clínica, principalmente quando serão testados agentes resinosos.

Durante o tratamento endodôntico, as soluções irrigadoras associadas à instrumentação biomecânica são necessárias, para remoção do material orgânico e inorgânico residual do interior dos canais radiculares. Segundo Berutti et al., (2003), a liberação de oxigênio proveniente do hipoclorito de sódio pode comprometer a polimerização dos agentes adesivos. Santos et al., (2006), avaliaram, através de ensaios de micro-tração, a força adesiva de um adesivo autocondicionante e resina composta à dentina da câmara pulpar. Observaram que, quando o $\mathrm{NaOCl}$ era empregado antes dos procedimentos adesivos, a força de adesão era estatisticamente menor. Já Pirani et al., (2005) demonstraram, através de microscopia eletrônica de varredura, que camadas híbridas formadas pelo Single Bond e pelo All-bond 2, após o uso de $\mathrm{NaOCl}$, não apresentam características de qualidade inferior, como infiltração incompleta de resina. Hayashi et al., (2005) observaram que os efeitos do NaOC dependem do tipo de sistema adesivo utilizado (autocondicionante ou não). 
Núcleos metálicos fundidos na maioria das vezes são cônicos, seguindo a anatomia do conduto radicular. A escolha de um formato cilíndrico teve a intenção de padronizar os preparos intrarradiculares, uma vez que os condutos eram levemente alargados com brocas cilíndricas do kit de pinos pré-fabricados C-Post. Neste estudo, na maioria dos casos, os canais não eram totalmente cilíndricos. As reentrâncias foram copiadas, garantindo adaptação aos N.M.F.s.

Quanto ao comprimento, as raízes dos dentes ficaram com um comprimento médio de $16 \mathrm{~mm}$, após terem as coroas removidas. A utilização de $10 \mathrm{~mm}$, para a porção intrarradicular do NMF, manteve suficiente remanescente apical (3 a 5mm), ao mesmo tempo alcançando comprimento adequado dentro da área supostamente envolta por osso alveolar. Além disto, a maioria dos trabalhos encontrados, avaliando a retenção de núcleos metálicos fundidos, utilizou este comprimento ou valores bem próximos (HABIB et al., 2005; ERTUGRUL; ISMAIL, 2005; MENANI, 2005; ALFREDO et al., 2006).

Os N.M.F.s. são fabricados com ligas nobres ou não-nobres (ASSIF; GORFIL, 1994). As ligas nobres de ouro têm sido relatadas na literatura científica como biocompatíveis, com alta resistência à corrosão e baixa rigidez, sendo as mais indicadas para a confecção de N.M.F.s. As ligas de metais nobres são altamente resistentes à corrosão, mas em contrapartida possuem um alto custo (FERNANDES et al., 2003), sendo que desde a década de 30, vêm sendo substituídas por ligas nãonobres. Desde então, segundo Zavanelli et a1., (2003), tanto o níquel-cromo (Ni-Cr) como o cobalto-cromo (Co-Cr), tornaram-se formulações populares pela economia e pelo papel que poderiam desempenhar como proposta de substituição às ligas de ouro.

As vantagens das ligas metálicas não-nobres são: baixo peso específico, alta resistência e baixo custo (KELLY; ROSE, 1983; CRAIG; POWERS, 2004). No entanto, alguns autores relatam que núcleos compostos de ligas não-nobres sofrem corrosão, e que este processo pode acarretar em fratura radicular, em função dos produtos de corrosão formados dentro do canal (ANGMAR-MANSSON et al., 1969; RUD; OMNELL, 1970; PETERSEN, 1971; LUU; WALKER, 1992; FERNANDES; DESSAI, 2001). 
Para a obturação endodôntica foi selecionado um cimento a base de resina epóxica contendo hidróxido de cálcio. O objetivo foi de prevenir qualquer interferência na polimerização do cimento resinoso, já que na literatura não há consenso quanto à influência do eugenol do cimento endodôntico sobre as propriedades do agente de fixação resinoso, quando da cimentação de retentores intrarradiculares (MILLSTEIN; NATHANSON, 1983; SCHWARTZ et al., 1998; MAYHEW et al., 2000; BOONE et al., 2001; ALFREDO et al., 2006).

Diferentes formas de preparo do espaço para pino são sugeridas. Podem ser utilizados calcadores ou condensadores de Paiva aquecidos (método térmico); limas e brocas de Peeso, Largo ou Gattes-Glidden (método mecânico) associados ou não à utilização de solventes de guta-percha (método químico-mecânico). A utilização de brocas de Peeso, Largo ou Gattes-Glidden é uma das técnicas mais populares. Estudos demonstram que não há diferença na infiltração apical, quando empregadas limas endodônticas e solventes, calcadores aquecidos ou brocas de Peeso, na remoção da guta-percha e preparo do espaço para pino, uma semana após a obturação (DICKEY et al., 1982; CAMP; TODD, 1983). Outros estudos obtiveram resultados semelhantes, porém, com o preparo sendo executado imediatamente após a obturação (MADISON; ZAKARIASEN, 1984; SUCHINA; LUDINGTON, 1985).

No presente estudo, foi proposta uma variação da técnica mecânica, de preparo do espaço para pino, compatível com as substâncias utilizadas. Esta técnica foi utilizada em estudo prévio, para o preparo do espaço para pinos de fibra de carbono, fixados com um cimento resinoso. $\mathrm{O}$ grupo onde foi utilizada a clorexidina em gel a $2 \%$ demonstrou resultados estatisticamente superiores ao grupo controle (soro fisiológico) (SILVA et al., 2005).

Para a utilização das substâncias, em conjunto com as brocas indicadas, foi padronizado um volume final de irrigação de $5 \mathrm{~mL}$ para todos os grupos. Nos grupos do gel de clorexidina, foi necessário um preparo parcial de $5 \mathrm{~mm}$ de profundidade, com a broca \#1, para criar um compartimento que acondicionasse o volume da primeira irrigação. Este tipo de procedimento era necessário porque estas duas substâncias precisariam estar em contato com a guta-percha durante sua remoção. A lubrificação das brocas e a remoção da guta-percha aos pedaços, sem que derreta, 
parece ser o mecanismo pelo qual a clorexidina proporciona adequada limpeza das paredes radiculares.

Para incluir os dentes em resina acrílica, foi utilizada uma maneira de evitar que forças laterais incidissem sobre o pino durante o teste de tração. Foi utilizado o longo eixo do canal radicular como guia, no momento da inclusão. Para isto seria necessário criar espaço para os pinos. Foram feitos os preparos, moldados os padrões e com estes inseridos nos condutos os dentes foram incluídos em resina acrílica. Este procedimento garantiu a inclusão dos dentes no longo eixo do conduto, já que após a fundição a cabeça dos núcleos ("core”) poderia estar alterada.

Para proteger os elementos dentais com os núcleos já cimentados estes foram envolvidos com uma camada de massa a base de resina epóxica (Durepoxi). Assim, os condutos foram protegidos dos efeitos do calor gerado pela polimerização da resina acrílica.

Dos quarenta espécimes avaliados, dois soltaram-se da resina epóxica. Neste caso, o ensaio de tração foi terminado com uma matriz que se apoiava no terço cervical do dente para que o núcleo pudesse ser removido.

Os resultados obtidos no presente estudo estão de acordo com os achados de Schmage et al., 2004 e Menani (2005). No primeiro estudo, foi avaliada a retenção de pinos pré-fabricados de titânio (passivos cônicos serrilhados) cimentados com quatro agentes resinosos e fosfato de zinco, como controle. Não houve diferença estatisticamente significante entre os cimentos resinosos e o grupo controle. Segundo os autores, o pino testado foi desenvolvido para ser cimentado com fosfato de zinco. Em função de apresentar boa adaptação as paredes dos canais radiculares e ser serrilhado, a cimentação com fosfato de zinco alcançou resultado semelhante a fixação com agentes resinosos.

No estudo de Menani (2005), foram utilizados núcleos metálicos fundidos, com a diferença de que eram constituídos de titânio e ouro. Foi avaliada a retenção destes núcleos quando cimentados com o cimento resinoso Panavia $\mathrm{F}$ e fosfato de zinco (controle). Não houve diferença estatisticamente significante entre o cimento resinoso e o grupo controle, para nenhuma das ligas utilizadas.

Em relação aos valores das médias de retenção e força de adesão obtidas neste estudo existiu concordância com alguns trabalhos e discordância de outros. Menani 
(2005) obteve valores médios de retenção de núcleos de titânio, cimentados com fosfato de zinco e Panavia F, de 27,72 Kgf e 25,42 Kgf, respectivamente. Para núcleos de ouro, cimentados com fosfato de zinco e Panavia $F$, os valores foram de 20,67 Kgf e 25,03 Kgf, respectivamente. Neste estudo, os valores de retenção de núcleos de níquel-cromo, cimentados com fosfato de zinco e Panavia $\mathrm{F}$, foram de 21,74 Kgf 17,48 $\mathrm{Kgf}$ respectivamente. As médias correspondentes do grupo experimental clorexidina foram 25,23 Kgf e 20,02 Kgf, respectivamente. Pode ser observada a semelhança dos valores.

Semelhança que também é observada em relação aos resultados de Ertugrul e Ismail (2005). No entanto, somente para os valores de força de adesão da Panavia $F$ (22,09 Kgf). O grupo cimentado com fosfato de zinco teve média de retenção de 34,35 Kgf. As diferenças de metodologia podem apontar para possíveis causas desta diferença. No estudo dos autores em questão, os dentes não receberam tratamento endodôntico. Todos os espécimes receberam condicionamento ácido, inclusive o grupo do fosfato. Outro fato relevante é a configuração dos núcleos. O comprimento dos núcleos era de $11 \mathrm{~mm}$ naquele e $10 \mathrm{~mm}$ neste estudo. O comprimento é reconhecidamente um fator interferente na retenção (STANDLEE et al., 1978; GLANTZ; NILNER, 1986). Os núcleos daquele estudo apresentavam o formato de um "coping curto", tipo de núcleo bastante usado em overdentures sobre raízes. Este tipo de núcleo apresenta adaptação ao remanescente coronário, abraçando toda a estrutura dental remanescente.Destaca-se ainda a diferença de desvio padrão do grupo do fosfato de zinco de 10,54 daquele contra 6,42 do presente estudo.

Neste estudo foram observados altos valores de desvio padrão. Segundo Utter et al., 1997, este fato é freqüentemente encontrado em estudos de retenção, em função das diferenças na procedência dos dentes em estudo. Este autor explica que é impossível padronizar a idade e demais condições dos dentes extraídos. Outros estudos também obtiveram altos valores de desvio padrão, para retenção de núcleos metálicos fundidos (SCHMAGE et al., 2004; MENANI, 2005; HABIB et al., 2005; ERTUGRUL; ISMAIL, 2005). Os valores de desvio padrão obtidos por Menani (2005), para núcleos de titânio e de ouro, cimentados com fosfato de zinco, foram de 5,40 e 10,77 respectivamente. Para os núcleos de titânio e ouro, cimentados com Panavia F, o desvio padrão foi de 5,67 e 8,83 respectivamente. Comparando com os 
valores de desvio padrão dos núcleos de níquel-cromo, cimentados com fosfato de zinco, obtidos neste estudo, 6,42 (controle) e 8,99 (experimental), observa-se a semelhança.

Alguns estudos sugerem que cimentos resinosos podem aumentar a retenção de pinos pré-fabricados (ASSIF; FERBER, 1982; GOLDMAN et al., 1984; CHAN et al., 1993; EL-MOWAFY; MILENKOVIC, 1994; MENDOZA et al., 1997; UTTER et al., 1997; DUNCAN; PAMEIJER, 1998). Outros trabalhos sugerem que não (RADKE et al., 1988; COHEN et al., 1992). Observando estes trabalhos notasse que os cimentos resinosos apresentam melhor desempenho em estudos onde foram utilizados pinos pré-fabricados. Este tipo de retentor dificilmente apresenta adaptação precisa às paredes do canal radicular. Segundo El-Mowafy e Milenkovic (1994), é de se esperar que o fosfato de zinco tenha seu desempenho prejudicado nesta situação. Sabe-se que o fosfato de zinco é um cimento que precisa apresentar espessura de película mínima, em torno de $25 \mu \mathrm{m}$, para que tenha resistência adequada (PHILLIPS, 1991). É possível que a adaptação tenha sido o ponto chave para o melhor desempenho dos cimentos resinosos em trabalhos de retenção com pinos préfabricados. Já quando foram utilizados N.M.F.s, os cimentos resinosos apresentaram resultados inferiores ao fosfato de zinco, ou ainda resultados similares, caso do presente estudo (SCHMAGE et al., 2004; MENANI, 2005; HABIB et al., 2005; ERTUGRUL; ISMAIL, 2005; ALFREDO et al., 2006).

A adesão à dentina profunda, encontrada na câmara pulpar e canal radicular, pode ser mais difícil de ser conseguida do que à dentina superficial. A dentina profunda apresenta túbulos dentinários de largo diâmetro e grande densidade de túbulos (PEREIRA et al., 1999). Não é possível utilizar técnicas incrementais dentro do canal radicular para minimizar os efeitos da contração de polimerização, considerando o alto fator cavitário (fator C) apresentado nesta região. Alguns autores afirmam que o estresse gerado na polimerização dos cimentos resinosos resulta em falhas na interface adesiva (MANOCCI et al., 2003; CALHEIROS et al., 2004; GORACCI et al., 2004). Nestas condições a contração de polimerização pode exceder a força de união à dentina radicular (TAY et al., 2005). A redução ou eliminação da quantidade de carga, nos cimentos resinosos em relação aos compósitos, necessária para o melhor escoamento do cimento, tende a aumentar a 
contração de polimerização (MAK et al., 2002). A contração volumétrica resultante da polimerização dos compósitos é da ordem de 1,5 a 5\% (FERRACANE, 2005). Destaca-se ainda que a Panavia F é um cimento resinoso dual e, no caso da cimentação de N.M.F. é impossível que a luz atinja todo o comprimento do canal. Somados todos estes fatores, o núcleo acaba ficando retido pelo íntimo contato do conjunto núcleo-agente cimentante através de retenção friccional.

O gluconato de clorexidina é um agente antibacteriano de amplo espectro que tem sua eficiência comprovada para o uso como irrigante endodôntico (JEANSONNE; WHITE, 1994; WHITE et al., 1997; KURUVILLA; KAMATH, 1998; FERRAZ et al., 2001) e medicação intracanal (SIQUEIRA; UZEDA, 1997; KOMOROWSKI et al., 2000; LENET et al., 2000). Wuerch et al., (2004) demonstraram que a clorexidina não afetou negativamente o selamento apical quando utilizada como medicação intracanal. Apresenta biocompatibilidade e efeito residual, efeito este que depende do tempo de exposição da dentina à clorexidina (BASRANI et al., 2002) e pode chegar a 12 semanas (ROSENTHAL et al., 2004). Quando usada como irrigante, a clorexidina proporciona um efeito residual comprovado de até 72 horas (WHITE et al., 1997). No caso do uso como substância auxiliar, no preparo de espaço para pino, o efeito conseguido na irrigação seria suficiente, já que os procedimentos de cimentação e confecção de coroas se encarregariam de vedar o canal. Neste caso, a possibilidade da clorexidina continuar agindo, após a cimentação, eliminaria os microrganismos que eventualmente pudessem restar no canal radicular.

Alguns estudos demonstram que o uso da clorexidina, como desinfetante de cavidades, não interfere na força de adesão de resinas compostas (PERDIGÃO et al., 1994; FILLER et al., 1994; DAMON et al., 1997), desde que a cavidade seja lavada para remoção da solução (GÜRGAN et al., 1999). Meiers e Shook (1996), obtiveram o mesmo resultado para o sistema adesivo Tenure, mas não para o adesivo Syntac, sugerindo que este efeito pode depender do material utilizado.

Pilo et al. (2001) observaram aumento da força de adesão de resinas compostas quando a dentina foi tratada com a clorexidina. No entanto, este resultado foi observado somente para um dos dois adesivos utilizados (One Step). Esta situação reforça que o efeito pode depender do material utilizado. Como as moléculas de clorexidina têm alta afinidade pela estrutura dentinária, estas poderiam agir como um 
surfactante, atraindo maior número de moléculas resinosas e colaborando com a adesão. Materiais que tenham maior afinidade por este conjunto podem ser favorecidos em detrimento de outros. O tempo de aplicação e a concentração da clorexidina no estudo em questão e no presente estudo são compatíveis.

Neste estudo o cimento resinoso utilizado não apresentou melhor desempenho quando foi utilizada a clorexidina, em relação ao grupo controle. Como exposto anteriormente, a íntima adaptação dos N.M.F.s as paredes do canal radicular, a espessura da película e as características substrato e do agente resinoso, parecem ter desempenhado papel fundamental na adesão.

Ferraz et al. (2001), demonstraram, pela microscopia eletrônica de varredura, propriedades superiores de limpeza das paredes dentinárias dos canais radiculares, pelo gluconato de clorexidina $2 \%$ em gel, quando utilizado como irrigante no tratamento endodôntico, quando comparado a água destilada, ao $\mathrm{NaOCl}$ à $5,25 \%$ e a clorexidina à $2 \%$ na forma líquida. É possível que, neste estudo, apesar da clorexidina gel ter proporcionado eficaz limpeza das paredes dos condutos, o íntimo contato dos N.M.F.s com as paredes tenha sido determinante para a retenção. A retenção pode ter sido proporcionada, quase que exclusivamente, pelo embricamento mecânico. Assim, a adesividade do agente resinoso não encontrou ambiente favorável para o aumento da retenção. Este aumento foi observado em outro estudo, onde a adaptação dos pinos pré-fabricados de fibra de carbono não era tão precisa como neste estudo, portanto o embricamento mecânico era menor e a espessura de película maior.

Como todo estudo in vitro este trabalho apresenta limitações. Ensaios de tração não representam todas as forças que pinos intrarradiculares sofrem clinicamente, quando em função. Além das diferentes direções de forças que se apresentam clinicamente, outros elementos estão associados a estes pinos, como os núcleos de preenchimento e as coroas protéticas, recebendo tais forças e as transferindo aos retentores intrarradiculares. No entanto, ensaios de tração são considerados testes válidos, pois, é necessário que os retentores intrarradiculares apresentem retenção e estabilidade dentro das raízes para que núcleos de preenchimento possam ser suportados por estes e por sua vez retenham as coroas protéticas que restauram e vedam os dentes tratados endodonticamente. Segundo Johnson e Sakumura (1978), forças que agem clinicamente sobre as interfaces 
retentor-cimento e cimento-dentina são forças laterais, de torção compressiva, de tensão e de cisalhamento. Considerando que forças de tração e compressão submetem as interfaces retentor-cimento e cimento-dentina o estresse de cisalhamento, a maioria das forças que agem clinicamente se manifesta de maneira semelhante. Sendo assim, estes autores afirmam que o uso do teste de tração traz uma boa estimativa da retenção alcançada clinicamente, pelos retentores intrarradiculares.

\section{Relevância clínica}

Em função dos resultados deste estudo, de estudo anterior (SILVA et al., 2005) e das propriedades do gluconato de clorexidina $2 \%$ em gel, seu emprego como substância auxiliar no preparo do espaço para pinos é de grande interesse clínico. Após a endodontia, existe um período em que o dente fica selado com um material provisório e quanto maior este período maior a microinfiltração coronária, podendo ocorrer recontaminação bacteriana dos canais radiculares. $\mathrm{O}$ uso da clorexidina pode desempenhar importante papel na eliminação destas bactérias, e diminuir a taxa de insucessos endodônticos, quando da necessidade de confecção de retentores intrarradiculares para reabilitação protética de dentes tratados endodonticamente.

No que diz respeito ao enfoque dado a este trabalho, o principal ponto de relevância clínica é a busca pela excelência, na restauração de dentes tratados endodonticamente. Os índices de sucesso do tratamento endodôntico variam muito, estando em uma faixa de 91,4-18,1\% (RAY; TROPE, 1995; TRONSTAD et al., 2000). Esta variação está associada ao cuidado dispensado a obturação total dos canais radiculares, incluindo a restauração definitiva. Ray e Trope (1995), observaram que dentes com bons tratamentos endodônticos e com restaurações bem adaptadas apresentavam altos índices de sucesso (91,4\%), e que este índice caia muito $(44,1 \%)$ quando os dentes apresentavam bons tratamentos endodônticos, porém restaurações deficientes. Observaram também que quando os dentes apresentavam tratamentos endodônticos deficientes, porém restaurações bem adaptadas, o mesmo índice voltava a subir $(67,6 \%)$, ressaltando a importância da qualidade da restauração 
definitiva. Ou seja, a infiltração coronária de bactérias, reinfectando o sistema de canais radiculares, faz com que aumente o índice de insucesso endodôntico. Esta infiltração que ocorre através de restaurações deficientes, é ainda mais intensa quando a saliva tem contato direto com o canal, como em procedimentos de preparo de espaço para pino, principalmente na falta do uso do isolamento absoluto.

Considerando as situações expostas, fica clara a necessidade de estabelecimento de um protocolo para o preparo do espaço para pinos.

No que diz respeito a confiabilidade dos resultados, e sua relevância clínica, é notório que testes estatísticos paramétricos são mais contundentes que os nãoparamétricos. Em estudo anterior, a clorexidina gel a $2 \%$ não influenciou negativamente a retenção de pinos de fibra de carbono fixados com um cimento resinoso (Hi-X, Bisco), assim como neste estudo, para núcleos metálicos fundidos cimentados com fosfato de zinco e Panavia F. Nestes dois estudos foi possível a utilização de testes estatísticos paramétricos (ANOVA).

Cimentos resinosos apresentam maior custo e grande sensibilidade a técnica. No entanto, o fosfato de zinco é um cimento amplamente testado dentro da odontologia. De fácil manuseio e baixo custo. A clorexidina também é uma substância amplamente utilizada na odontologia. Sua formulação em gel tem demonstrado não influenciar negativamente o selamento apical, de dentes tratados endodonticamente, quando utilizada como irrigante ou medicação intracanal. São bem conhecidos sua biocompatibilidade, seu efeito antimicrobiano e efeito residual.

Deve-se ressaltar as limitações que um estudo in vitro apresenta. A soma das informações obtidas dos estudos in vitro suporta a possibilidade de realização de um estudo clínico onde o protocolo de preparo do espaço para pino sugerido a seguir pode ser utilizado.

Preparo do espaço para núcleos metálicos fundidos, utilizando a clorexidina em gel a $2 \%$, como auxiliar, para serem cimentados com fosfato de zinco:

1. Obtenção de radiografia periapical do elemento e mensuração do comprimento radicular;

2. Seleção do instrumento compatível com o diâmetro do canal radicular; 
3. Isolamento absoluto ou relativo efetivo;

4. Remoção de 2 a $3 \mathrm{~mm}$ de guta-percha, criando espaço para a clorexidina;

5. Irrigação com a clorexidina em gel a 2\%;

6. Remoção do restante da guta-percha, em pequenas quantidades, intercalando irrigações com o gel;

7. Alcançado o comprimento de trabalho, irrigar com o gel novamente, alargar as paredes (se necessário) e irrigar com soro fisiológico;

8. Calcar o remanescente de guta-percha.

A utilização de um agente antimicrobiano, como o gel de clorexidina à $2 \%$, serve como lubrificante das brocas e constitui cuidado adicional, principalmente em casos onde, após o tratamento endodôntico, este dente permaneceu selado provisoriamente por algum tempo. Seu uso não substitui os outros cuidados, como o uso de isolamento absoluto ou relativo. O bom senso indicará em que situações clínicas utilizar cada um deles. O importante é que não pode existir nenhum contato de fluídos bucais com o interior dos canais radiculares. 
7 CONCLUSÃO 
1. Considerando os resultados deste estudo, conclui-se que:

Não houve diferença na retenção de núcleos metálicos fundidos, cimentados com Fosfato de Zinco ou cimento resinoso (Panavia F), após o preparo do espaço para pino com soro fisiológico ou gluconato de clorexidina em gel a $2 \%$. 


\section{REFERÊNCIAS BIBLIOGRÁFICAS}


1. ALBUQUERQUE, R.C.; Pinos intra-radiculares pré-fabricados. In: CARDOSO, R.J.A.; GONÇALVES, E.A.N. Oclusão/ATM, prótese, prótese sobre Implante e prótese bucomaxilofacial. 1ed. São Paulo, Artes Médicas, 2002. Cap.19, p.441-62.

2. ALFREDO, E.; DE SOUZA, E.S.; MARCHESAN, M.A.; PAULINO, S.M.; GARIBASILVA, R.; SOUSA-NETO, M.D. Effect of eugenol-based endodontic cement on the adhesion of intraradicular posts. Braz. Dent. J., Ribeirão Preto, v.17, n.2, p.130-3, 2006.

3. ANGMAR-MANSSON, B.; OMNELL, K.A.; RUD, J. Root fractures due to corrosion. 1. Metallurgical aspects. Odontol. Revy., v.20, n.3, p.245-65, 1969.

4. ASSIF, D.; FERBER, A. Retention of dowels using a composite resin as a cementing medium. J. Prosthet. Dent., St. Louis, v.48, n.3, p.292-6, September 1982.

5. ASSIF, D.; GORFIL, C. Biomechanical considerations in restoring endodontically treated teeth. J. Prosthet. Dent., St. Louis, v.71, n.6, p.565-7, June 1994.

6. ASSIF, D; BITENSKI, A.; PILO, R.; OREN, E. Effect of post design on resistance to fracture of endodontically treated teeth with complete crowns. J. Prosthet. Dent., St. Louis, v.69, n.1, p.36-40, January 1993.

7. BASRANI, B.; SANTOS, M., TJÄDERHANE, L.; GRAD, H.; GORDUYSUS, O.; HUANG, J.; LAWRENCE, H.P.; FRIEDMAN, S. Substantive antimicrobial activity in chlorhexidine-treated human root dentin. Oral Surg. Oral Med. Oral Pathol. Oral Radiol. Endod., St. Louis, v.94, n.2, p.240-5, August 2002.

8. BERGMAN, B.; LUNDQUIST, P.; SJÖGREN, U.; SUNDQUIST, G. Restorative and endodontic results after treatment with cast posts and cores. J. Prosthet. Dent., St. Louis, v.61, n.1, p.10-5, January 1989.

9. BERUTTI, E.; ORSI, M.V.; GRANDINI, S. O tratamento endodôntico. In: SCOTTI, R.; FERRARI, M. Pinos de fibra: considerações teóricas e aplicações clínicas. São Paulo, Artes Médicas, 2003.

10. BOONE, K.J.; MURCHISON, D.F.; SCHINDLER, W.G.; WALKER, W.A. Post retention: the effect of sequence of post-space preparation, cementation time, and different sealers. J. Endod., Chicago, v.27, n.12, p.768-71, 2001.

11. BRÄNNSTRÖM, M. Smear layer: Pathological and treatment considerations. Oper. Dent., Seattle, v.3, n.(Suppl 3), p.35-41, March 1984.

12. BURNS, R.; HERBRANSON, E.J. Tooth morphology and cavity preparation. In: COHEN, S.; BURNS, R.C. Pathways of the pulp. $8^{\text {th }}$ ed. St. Louis, CV Mosby, 2002, p.173-229. 
13. CALHEIROS, F.C.; BRAGA, R.R.; KAWANO, Y.; BALLESTER, R.Y. Relationship between contraction stress and degree of conversion in restorative composites. Dent. Mater., v.20, n.10, p.939-46, December 2004.

14. CAMP, L.R.; TODD, M.J. The effect of dowel preparation on the apical seal of three common obturation techniques. J. Prosthet. Dent., St. Louis, v.50, n.5, p.664-6, November 1983.

15. CHAN, F.W.; HARCOURT, J.K.; BROCKHURST, P.J. The effect of post adaptation in the root canal on retention of posts cemented with various cements. Aus. Dent. J., Sidney, v.38, n.1, p.39-45, February 1993.

16. COHEN, B.I.; MUSIKANT, B.L.; DEUTSCH, A.S. Comparison of retentive properties of four post systems. J. Prosthet. Dent., St. Louis, v.68, n.2, p.264-8, August 1992.

17. COHEN, S.; BURNS, R.C. Pathways of the pulp. 8th ed. St. Louis, CV Mosby, 2002. $1031 \mathrm{p}$.

18. CRAIG, R.G.; POWERS, J.M. Materiais dentários restauradores. São Paulo, Santos Editora, 2004.

19. DAMETTO, F.R.; FERRAZ, C.C.; DE ALMEIDA GOMES, B.P.; ZAIA, A.A.; TEIXEIRA, F.B.; DE SOUZA-FILHO, F.J. In vitro assessment of the immediate and prolonged antimicrobial action of chlorhexidine gel as an endodontic irrigant against Enterococcus faecalis. Oral Surg. Oral Med. Oral Pathol. Oral Radiol. Endod., St. Louis, v.99, n.6, p.768-72, June 2005.

20. DAMON, P.R.; BISHARA, S.E.; OLSEN, M.E.; JAKOBSEN, J.R. Bond strength following the application of chlorhexidine on etched enamel. Angle Orthod., Appleton, v.67, n.3, p.169-71, June 1997.

21. DE DEUS, Q. D., Endodontia. Quinta Edição. Medsi, 1992.

22. DEAN, J.P.; JEANSONNE, B.G.; SARKAR, N. In vitro evaluation of a carbon fiber post. J. Endod., Chigago, v.24, n.12, p.807-10, December 1998.

23. DICKEY, D.J.; HARRIS, G.Z.; LEMON, R.R.; LUEBKE, R.G. Effect of post space preparation on apical seal using solvent techniques and Peeso reamers. J. Endod., Chigago, v.8, n.8, p.351-4, August 1982.

24. DUNCAN, J.P.; PAMEIJER, C.H. Retention of parallel-sided titanium posts cemented with six luting agents: An in vitro study. J. Prosthet. Dent., St. Louis, v.80, n.4, p.5-9, October 1998. 
25. EICK, J.D.; WILKO, R.A.; ANDERSON, C.H.; SORENSEN, S.E. Scanning electron microscopy of cut tooth surfaces and identification of debris by of the electron microprobe. J. Dent. Res., Chigago, v.49, n. 6, p.1359-68, November-December 1970.

26. EISSMAN, H.F.; RADKE, R. Postendodontic restoration. In: COHEN, S.; BURNS, R.C. Pathways of the pulp. $4^{\text {th }}$ ed. St. Louis, CV Mosby, 1987, p640-3.

27. EL-MOWAFY, O.M.; MILENKOVIC, M. Retention of Paraposts cemented with dentin-bonded resin cements. Oper. Dent., Seattle, v.19, n.5, p.176-82, Sep.October1994.

28. ERCAN, E.; DALLI, M.; DULGERGIL, C.T. In vitro assessment of the effectiveness of chlorhexidine gel and calcium hydroxide paste with chlorhexidine against Enterococcus faecalis and Candida albicans. Oral Surg. Oral Med. Oral Pathol. Oral Radiol. Endod., St. Louis, v.102, n.2, p.27-31, August 2006.

29. ERTUGRUL, H.Z.; ISMAIL, Y.H. An in vitro comparison of cast metal dowel retention using various luting agents and tensile loading. J. Prosthet. Dent., St. Louis, v.93, n.5, p.446-52, May 2005.

30. FERNANDES, A.S.; DESSAI, G.S. Factors affecting the fracture resistance of postcore reconstructed teeth: a review. Int. J. Prosthodont., Toronto, v.14, n.4, p.355-63, 2001.

31. FERNANDES, A.S.; SHETTY, S.; COUTINHO, I. Factors determining post selection: a literature review. J. Prosthet. Dent., St. Louis, v.90, n.6, p.556-62, December 2003.

32. FERRACANE, J.L. Developing a more complete understanding of stresses produced in dental composites during polymerization. Dent. Mater., v.21, n.1, p.36-42, January 2005 .

33. FERRAZ, C.C.; FIGUEIREDO DE ALMEIDA GOMES, B.P.; ZAIA, A.A.; TEIXEIRA, F.B.; DE SOUZA-FILHO, F.J. In vitro assessment of the antimicrobial action and the mechanical ability of chlorhexidine gel as an endodontic irrigant. $\mathbf{J}$. Endod., Chigago, v.27, n.7, p.452-5, July 2001.

34. FILLER, S.J.; LAZARCHIK, D.A.; GIVAN, D.A.; RETIEF, D.H; HEAVEN, T.J. Shear bond strengths of composite to chlorhexidine-treated enamel. Am. J. Dent., St. Antonio, v.7, n.2, p.85-8, April 1994.

35. FRANK, A.L. Protective coronal coverage of the pulpless tooth. J.A.D.A., Chigago, v.59, n.5, p.895-900, November 1959.

36. GLANTZ, P.O.; NILNER, K. Root canal posts- some prosthodontic aspects. Endo. Dent. Traumatol., Copenhagen, v.2, n.4, p.231-6, August 1986. 
37. GOLDMAN, M.; DEVITRE, R.; PIER, M. Effect of the dentin smeared layer on tensile strength of cemented posts. J. Prosthet. Dent., St. Louis, v.52, n.4, p.485-8, October 1984.

38. GORACCI, C.; TAVARES, A.U.; FABIANELLI, A.; MONTICELLI, F.; RAFFAELLI, O.; CARDOSO, P.C.; TAY, F.; FERRARI, M. The adhesion between fiber posts and root canal walls: comparison between microtensile and push-out bond strength measurements. Eur. J. Oral. Sci., v.112, n.4, p.353-61, August 2004.

39. GÜRGAN, S.; BOLAY, Ş.; KIREMITÇI, A. Effect of disinfectant application methods on the bond strength of composite to dentin. J. Oral Rehabil., Oxford, v.26, n.10, p.836-40, October 1999.

40. GUTMANN, J.L. The dentin-root complex: anatomic and biologic considerations in restoring endodontically treated teeth. J. Prosthet. Dent., St. Louis, v.67, n.4, p.458-67, April 1992.

41. GUZY, G.E.; NICHOLLS, J.I. In vitro comparison of intact endodontically treated teeth with and without endo-post reinforcement. J. Prosthet. Dent., St. Louis, v.42, n.1, p.39-45, July 1979.

42. GWINNETT, J.A. Smear layer: Morphological considerations. Oper. Dent., Seattle, v.3, n.(Suppl 3), p.3-12, March 1984.

43. HABIB, B.; VON FRAUNHOFER, J.A.; DRISCOLL, C.F. Comparison of two luting agents used for the retention of cast dowel and cores. J. Prosthodont., v.14, n.3, p.1649, September 2005.

44. HATZIKYRIAKOS, A.H.; REISIS, G.I.; TSINGOS, N. A 3-year postoperative clinical evaluation of posts and cores beneath existing crowns. J. Prosthet. Dent., St. Louis, v.67, n.4, p.454-8, April 1992.

45. HAYASHI, M.; TAKAHASHI, Y.; HIRAI, M.; IWAMI, Y.; IMAZATO, S.; EBISU, S. Effect of endodontic irrigation on bonding of resin cement to radicular dentin. Eur. J. Oral Sci., v.113, n.1, p.70-6, February 2005.

46. HEDLUND, S.O.; JOHANSSON, N.G.; SJOGREN, G. Retention of prefabricated and individually cast root canal posts in vitro. Br. Dent. J., v.195, n.3, p.155-8, discussion 147, August 2003.

47. HELFER, A.R.; MELNICK, S.; SCHILDER, H. Determination of the moisture content of vital and pulpless teeth. Oral Surg., St. Louis, v.34, n.4, p.661-70, October 1972. 
48. HELING, I.; GORFIL, C.; SLUTZKY, H.; KOPOLOVIC, K.; ZALKIND, M.; SLUTZKY-GOLDBERG, I. Endodontic failure caused by inadequate restorative procedures: review and treatment recommendations. J. Prosthet. Dent., St. Louis, v.87, n.6, p.674-8, June 2002.

49. HEYDECKE, G.; PETERS, M.C. The restoration of endodontically treated, singlerooted teeth with cast or direct posts and cores: a systematic review. J. Prosthet. Dent., St. Louis, v.87, n.4, p.380-6, April 2002.

50. HOLMES, D.C.; DIAZ-ARNOLD, A.M.; LEARY, J.M. Influence of post dimension on stress distribution in dentin. J. Prosthet. Dent., St. Louis, v.75, n.2, p.140-7, February 1996.

51. HUANG, T.J.; SCHILDER, H.; NATHANSON, D. Effects of moisture content and endodontic treatment on some mechanical properties of human dentin. J. Endod., Chigago, v.18, n.5, p.209-15, May 1992.

52. HUNTER, A.J.; FEIGLIN, B.; WILLIAMS, J.F. Effects of post placement on endodontically treated teeth. J. Prosthet. Dent., St. Louis, v.62, n.2, p.166-72, August 1989.

53. ISIDOR, F.; ODMAN, P.; BRONDUM, K. Intermittent loading of teeth restored using prefabricated carbon fiber posts. Int. J. Prosthod., Toronto, v.9, n.6, p.131-6, April 1996.

54. JEANSONNE, M.J.; WHITE, R.R. A comparison of $2.0 \%$ chlorhexidine gluconate and $5.25 \%$ sodium hypochlorite as antimicrobial endodontic irrigants. J. Endod., Chigago, v.20, n.6, p.276-8, June 1994.

55. JOHNSON, J.K.; SAKUMURA, J.S. Dowel form and tensile force. J. Prosthet. Dent., St. Louis, v.40, n.6, p.645-9, December 1978.

56. KELLY, J.R.; ROSE, T.C. Nonprecious alloys for use in fixed prosthodontics: a literature review. J. Prosthet. Dent., St. Louis, v.49, n.3, p.363-70, 1983.

57. KOMOROWSKI, R.; GRAD, H.; WU, X.Y.; FRIEDMAN, S. Antimicrobial substantivity of chlorhexidine-treated bovine root dentin. J. Endod., Chigago, v.26, n.6, p.315-7, June 2000.

58. KURUVILLA, J.R.; KAMATH, M.P. Antimicrobial activity of $2.5 \%$ sodium hypochlorite and $0.2 \%$ chlorhexidine gluconate separately and combined, as endodontic irrigants. J. Endod., Chigago, v.24, n.7, p.472-6, July 1998.

59. LENET, B.J.; KOMOROWSKI, R.; WU, X.Y.; HUANG, J.; GRAD, H.; LAWRENCE, H.P.; FRIEDMAN, S. Antimicrobial substantivity of bovine root dentin exposed to different chlorhexidine delivery vehicles. J. Endod., Chigago, v.26, n.11, p.652-5, November 2000. 
60. LOVDAHL, P.E.; NICHOLLS, J.I. Pin-retained amalgam cores vs. cast gold dowelcores. J. Prosthet. Dent., St. Louis, v.38, n.5, p.507-14, November 1977.

61. LUU, K.Q.; WALKER, R.T. Corrosion of a nonprecious metal posts: a case report. Quintessence Int., Berlim, v.23, n.6, p.389-92, 1992.

62. MADISON, S.; ZAKARIASEN, K..L. Linear and volumetric analysis of apical leakage in teeth prepared for posts. J Endod., Chigago, v.10, n.9, p.422-7, September 1984.

63. MAGALHÃES, F. Análise comparativa da profundidade de fratura de dentes tratados endodonticamente restaurados com núcleos metálicos fundidos e núcleos de fibra de carbono. Tese de mestrado apresentada a Faculdade de Odontologia de Ribeirão PretoUSP, Ribeirão Preto, 2000. 60 p.

64. MAK, Y.F.; LAI, S.C.; CHEUNG, G.S.; CHAN, A.W.; TAY, F.R.; PASHLEY, D.H. Micro-tensile bond testing of resin cements to dentin and an indirect resin composite. Dent. Mater., v.18, n.8, p.609-21, December 2002.

65. MANNOCCI, F.; SHERRIFF, M.; FERRARI, M.; WATSON, T.F. Microtensile bond strength and confocal microscopy of dental adhesives bonded to root canal dentin. Am. J. Dent., St. Antonio, v.14, n.4, p.200-4, August 2001.

66. MARTINEZ-INSUA, A.; SILVA, L.; RILO, B.; SANTANA, V. Comparison of the fracture resistance of pulpless teeth restored with a cast post and core or carbon-fiber post with a composite core. J. Prosthet. Dent., St. Louis, v.80, n.5, p.527-32, November 1998.

67. MAYHEW, J.T.; WINDCHY, A.M.; GOLDSMITH, L.J.; GETTLEMEN, L. Effect of root canal sealers and irrigation agents on retention of preformed posts luted with a resin cement. J. Endod., Chigago, v.26, n.6, p.341-4, June 2000.

68. MEIERS, J.C.; SHOOK, L.W. Effect of disinfectants on the bond strength of composite to dentin. Am. J. Dent., St. Antonio, v.9, n.1, p.11-4, February 1996.

69. MENANI, L. R. Avaliação comparativa da influência do tratamento superficial e do agente cimentante na retenção de núcleos metálicos fundidos em titânio c.p. Tese de mestrado apresentada a Faculdade de Odontologia de Ribeirão Preto-USP, Ribeirão Preto, 2005. 126 p.

70. MENDOZA, D.B.; EAKLE, S; KAHL, E.A.; HO, R. Root reinforcement with a resinbonded preformed post. J. Prosthet. Dent., St. Louis, v.78, n.1, p.10-4, July 1997.

71. MENDOZA, D.B.; EAKLE, W.S. Retention of posts cemented with various dentinal bonding cements. J. Prosthet. Dent., St. Louis, v.72, n.6, p.591-4, December 1994. 
72. MEZZOMO, E.; MASSA, F.; SUZUKI, R.M. Fracture resistance of teeth restored with 2 different post-and-core designs fixed with 2 different luting cements: an in vitro study. Part II. Quintessence Int., Berlim, v.37, n.6, p.477-84, June 2006.

73. MEZZOMO, E.; SUZUKI, R.M. Reabilitação oral contemporânea. 1ed., São Paulo: Livraria Santos, 2006.

74. MILLSTEIN, P.L.; NATHANSON, D. Effect of eugenol cements on cured composite resin. J. Prosthet. Dent., St. Louis, v.50, n.2, p.211-5, August 1983.

75. MORGANO, S.M. Restoration of pulpless teeth: Application of traditional principles in present and future contexts. J. Prosthet. Dent., St. Louis, v.75, n.4, p.375-80, April 1996.

76. MORGANO, S.M.; BRACKETT, S.E. Foundation restorations in fixed prosthodontics: current knowledge and future needs. J. Prosthet. Dent., St. Louis, v.82, n.6, p.643-57, December 1999.

77. NAUMANN, M.; KIESSLING, S.; SEEMANN, R. Treatment concepts for restoration of endodontically treated teeth: A nationwide survey of dentists in Germany. $\mathbf{J}$. Prosthet. Dent., St. Louis, v.96, n.5, p.332-8, November 2006.

78. NEWMAN, M.P.; YAMAN, P.; DENNISON, J.; RAFTER, M.; BILLY, E. Fracture resistance of endodontically treated teeth restored with composite posts. $\underline{\text { J. Prosthet. }}$ Dent., v.89, n.4, p.360-7, April 2003.

79. OLIVEIRA, D.P. Avaliação in vitro da remoção de material obturador empregando diferentes técnicas durante o retratamento endodôntico. Tese de mestrado apresentada a Faculdade de Odontologia de Piracicaba-UNICAMP, Piracicaba, 2002. 74p.

80. PANIGHI, M.; G'SELL, C. Influence of calcium concentration on the dentin wettability by an adhesive. J. Biomed. Mat. Res., New York, v.26, n.8, p.1081-9, August 1992.

81. PAPA, J.; CAIN, C.; MESSER, H.H. Moisture content of vital vs. endodontically treated teeth. Endo. Dent. Traumatol., Copenhagen, v.10, n.2, p.91-3, April 1994.

82. PASHLEY, D.H. Smear layer: Physiological considerations. Oper. Dent., Seattle, v.3, n.(Suppl 3), p.13-29, March 1984.

83. PEREIRA, P.N.R.; OKUDA, M.; SANO, H.; YOSHIKAWA, T.; BURROW, M.F.; TAGAMI, J. Effect of intrinsic wetness and regional difference on dentin bond strength. Dent. Mater., v.15, n.1, p.46-53, January 1999. 
84. PERDIGÃO, J.; DENEHY, G.E.; SWIFT, E.J.Jr. Effects of chlorhexidine on dentin surfaces and shear bond strength. Am. J. Dent., St. Antonio, v.7, n.2, p.81-84, April 1994.

85. PETERSEN, K.B. Longitudinal root fracture due to corrosion of an endodontic post. J. Can. Dent. Assoc., v.37, n.2, p.66-8, 1971.

86. PHILLIPS, R.W. Skinner's Science of Dental Materials. 7rd ed. Philadelphia, W.B. Saunders Company, 1991, p.501-26.

87. PILO, R.; CARDASH, H.S.; OZ-ARI, B.; BEM-AMAR, A. Effect of preliminary treatment of the dentin surface of the dentin surface on the shear bond strength of resin composite to dentin. Oper. Dent., Seattle, v.26, n.6, p.569-75, November-December 2001 .

88. PINKLEY, V.A.; MORRIS, D.R. Use of nonprecious metal for cast dowel and core. J. Prosthet. Dent., St. Louis, v.32, n.1, p.78-9, July 1974.

89. PIRANI, C.; CHERSONI, S.; FOSCHI, F.; PIANA, G.; LOUSHINE, R.J.; TAY, F.R.; PRATI, C. Does hybridization of intraradicular dentin really improve fiber post retention in endodontically treated teeth? J. Endod., Chigago, v.31, n.12, p.891-4, December 2005.

90. PLASMANS, P.J.J.M.; WELLE, P.R.; VRIJOEF, M.M.A. In vitro resistance of composite resin dowel and cores. J. Endod., Chigago, v.14, n.6, p.300-4, June 1988.

91. PURTON, D.G.; LOVE, R.M. Rigidity and retention of carbon fiber versus stainless steel root canal posts. Int. Endo. J., Oxford, v.29, n.4, p.262-5, July 1996.

92. PURTON, D.G.; PAYNE, J.A. Comparison of carbon fiber and stainless root canal posts. Quintessence Int., Berlim, v.27, n.2, p.93-7, February 1996.

93. RADKE, R.A.; BARKHORDAR, R.A.; PODESTA, R.E. Retention of cast endodontic posts: comparison of cementing agents. J. Prosthet. Dent., St. Louis, v.59, n.3, p. 31820, March 1988.

94. RAY, H.A.; TROPE, M. Periapical status of endodontically treated teeth in relation to the technical quality of the root filling and the coronal restoration. Int. Endo. J., Oxford, v.28, n.1, p.12-8, January 1995.

95. REEH, E.S.; MESSER, H.H.; DOUGLAS, W.H. Reduction in tooth stiffness as a result of endodontic and restorative procedures. J. Endod., Chicago, v.15, n.11, p.512-6, November 1989.

96. ROSEN, H. Operative procedures on mutilated endodontically treated teeth. J. Prosthet. Dent., St. Louis, v.11, n.5, p.973-86, September-October 1961. 
97. ROSENSTIEL, S.F.; LAND, M.F.; FUJIMOTO, J. Restauração de dentes tratados endodonticamente. In: Prótese Fixa Contemporânea. 3ed., São Paulo, Livraria Santos Editora, 2005, p.272-312.

98. ROSENTHAL, S.; SPANGBERG, L.; SAFAVI, K. Chlorhexidine substantivity in root canal dentin. Oral Surg. Oral Med. Oral Pathol. Oral Radiol. Endod., St. Louis, v.98, n.4, p.488-92, October 2004.

99. RUD, J.; OMNELL, K.A. Root fractures due to corrosion resistance of commercial NiCr dental casting alloy. Scand. J. Dent. Res., v.78, n.5, p.397-403, 1970.

100. RUEPIMG, D.R.; LUND, M.R.; SCHNELL, R.J. Retention of dowels subjected to tensile and torsional forces. J. Prosthet. Dent., St. Louis, v.41, n.2, p.159-62, February 1979.

101. SANTOS, J.N.; CARRILHO, M.R.O.; DE GOES, M.F.; ZAIA, A.A.; GOMES, B.P.; SOUZA-FILHO, F.J.; FERRAZ, C.C. Effect of chemical irrigants on the bond strength of a self-etching adhesive to pulp chamber dentin. J. Endod., Chicago, v.32, n.11, p.1088-90, Epub November 2006 September 15.

102. SAUPE, W.A.; GLUSKIN, A.H.; RADKE, R.A.Jr. A comparative study of fracture resistance between morphologic dowel and cores and a resin-reinforced dowel system in the intraradicular restoration of structurally compromised roots. Quintessence Int., Berlim, v.27, n.7, p.483-91, July 1996.

103. SCHMAGE, P.; SOHN, J.; NERGIZ, I.; OZCAN, M. Various conditioning methods for root canals influencing the tensile strength of titanium posts. J. Oral. Rehabil., Oxford, v.31, n.9, p.890-4, September 2004.

104. SCHWARTZ, R.S.; MURCHISON, D.F.; WALKER, W.A. Effects of eugenol and noneugenol endodontic sealer cements on post retention. J. Endod., Chigago, v.24, n.8, p.564-7, August 1998.

105. SEDGLEY, C.M.; MESSER, H.H. Are endodontically treated teeth more brittle? J. Endod., Chicago, v.18, n.7, p.332-5, July 1992.

106. SERAFINO, C.; GALLINA, G.; CUMBO, E.; FERRARI, M. Surface debris of canal walls after post space preparation in endodontically treated teeth: a scanning electron microscopic study. Oral Surg. Oral Med. Oral Pathol. Oral Radiol. Endod., St. Louis, v.97, n.3, p.381-7, March 2004.

107. SHILLINGBURG, H.T.; HOBO, S.; WHITSETT, L.D.; JACOBI, R.; BRACKETT, S.E. Fundamentos de prótese fixa. $3^{\text {rd }} \mathrm{ed}$, São Paulo, Quintessence Publishing Co, 1998. $472 \mathrm{p}$. 
108. SIDOLI, G.E.; KING, P.A.; SETCHELL, D.J. An in vitro evaluation of a carbon fiber-based post and core system. J. Prosthet. Dent., St. Louis, v.78, n.1, p.5-9, July 1997.

109. SILVA, R.S.; ANTUNES, R.P.A.; FERRAZ, C.C.R.; ORSI, I.A. The effect of the use of $2 \%$ chlorhexidine gel in post-space preparation on carbon fiber post retention. Oral Surg. Oral Med. Oral Pathol. Oral Radiol. Endod., St. Louis, v.99, n.3, p.3727, March 2005.

110. SIQUEIRA, J.F.Jr.; UZEDA, M. Intracanal Medicaments: Evaluation of the antibacterial effects of chlorhexidine, metronidazole, and calcium hydroxide associated with three venicles. J. Endod., Chigago, v.23, n.3, p.167-9, March 1997.

111. SORENSEN, J.A.; ENGELMAN, M.J. Ferrule design and fracture resistance of endodontically treated teeth. J. Prosthet. Dent., St. Louis, v.63, n.5, p.529-36, May 1990.

112. STANDLEE, J.P.; CAPUTO, A.A.; HANSON, E.C. Retention of endodontic dowels: effects of cement, dowel length, diameter, and design. J. Prosthet. Dent., St. Louis, v.39, n.4, p.401-5, April 1978.

113. SUCHINA, J.A.; LUDINGTON, J.R.Jr. Dowel space preparation and the apical seal. J. Endod., Chigago, v.11, n.1, p.11-7, January 1985.

114. TAY, F.R.; LOUSHINE, R.J.; LAMBRECHTS, P.; WELLER, R.N.; PASHLEY, D.H. Geometric factors affecting dentin bonding in root canals: a theoretical modeling approach. J. Endod., Chicago, v.31, n.8, p.584-9, August 2005.

115. TORBJÖRNER, A.; KARLSSON, S.; ÖDMAN, P.A. Survival rate and failure characteristics for two post designs. J. Prosthet. Dent., St. Louis, v.73, n.5, p.439-44, May 1995.

116. TRONSTAD, L.; ASBJORNSEN, K.; DOVING, L.; PEDERSEN, I.; ERIKSEN, H.M. Influence of coronal restorations on the periapical health of endodontically treated teeth. Endo. Dent. Traumatol., Copenhagen, v.16, n.5, p.218-21, October 2000.

117. UTTER, J.D.; WONG, B.H.; MILLER, B.H. The effect of cementing procedures on retention of prefabricated metal posts. J.A.D.A., Chigago, v.128, n.8, p.1123-7, August 1997.

118. VIANNA, M.E.; GOMES, B.P.; BERBER, V.B.; ZAIA, A.A.; FERRAZ, C.C.; DE SOUZA-FILHO, F.J. In vitro evaluation of the antimicrobial activity of chlorhexidine and sodium hypochlorite. Oral Surg. Oral Med. Oral Pathol. Oral Radiol. Endod., St. Louis, v.97, n.1, p.79-84, January 2004. 
119. VIANNA, M.E.; HORZ, H.P.; GOMES, B.P.; CONRADS, G. In vivo evaluation of microbial reduction after chemo-mechanical preparation of human root canals containing necrotic pulp tissue. Int. Endod. J., Oxford, v.39, n.6, p.484-92, June 2006.

120. VIVACQUA-GOMES, N.; GURGEL-FILHO, E.D.; GOMES, B.P.; FERRAZ, C.C.; ZAIA, A.A.; SOUZA-FILHO, F.J. Recovery of Enterococcus faecalis after single- or multiple-visit root canal treatments carried out in infected teeth ex vivo. Int. Endod. J., Oxford, v.38, n.10, p.697-704, October 2005.

121. WEINE, F.S.; WAX, A.H.; WENCKUS, C.S. Retrospective study of tapered, smooth post systems in place for 10 years or more. J. Endod., Chigago, v.7, n.6, p.29397, June 1991.

122. WHITE, R.R.; HAYS, G.L.; JANER, L.R. Residual antimicrobial activity after canal irrigation with chlorhexidine. J. Endod., Chigago, v.23, n.4, p.229-31, April 1997.

123. WUERCH, R.M.; APICELLA, M.J.; MINES, P.; YANCICH, P.J.; PASHLEY, D.H. Effect of $2 \%$ chlorhexidine gel as an intracanal medication on the apical seal of the root-canal system. J. Endod., Chicago, v.30, n.11, p.788-91, November 2004.

124. ZAVANELLI, R.A.; HENRIQUES, G.E.P; MESQUITA, M.A.; NÓBILO, M.A.A.; CONTRERAS, E.F.R.; ZAVANELLI, A.C. Processo de fundição do titânio e de suas ligas na área de reabilitação oral. P.C.L., v.28, n.5, p.505-15, 2003. 
9 ANEXO 


\section{Anexo}

Ofício do Comitê de Ética em Pesquisa.

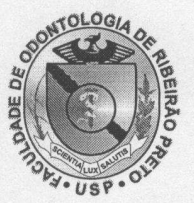

UNIVERSIDADE DE SÃO PAULO

FACULDADE DE ODONTOLOGIA DE RIBEIRÃO PRETO COMITÊ DE ÉTICA EM PESQUISA

Avenida do Café, $s / n^{\circ}$ - Telefone: (016) 3602-3963

$14040-904$ - Ribeirão Preto - SP - Brasil

Fax: (016) 3633-0999

OF.CEP/036/FORP/28022007

Prezado(a) Professor(a),

De ordem da Senhora Coordenadora do Comitê de Ética em Pesquisa desta Faculdade, informamos que o referido Comitê, em sua $75^{\text {a }}$ Sessão realizada no dia 28 de fevereiro de 2007, analisou e aprovou o Relatório Final do Projeto de Pesquisa envolvendo seres humanos intitulado: "Efeito do gluconato de clorexidina a $2 \%$ em gel usado durante o preparo intra-radicular na retenção de núcleos metálicos fundidos"

Solicitamos que quando da publicação do trabalho em forma de artigo, seja entregue uma fotocópia na Secretaria do Comitê.

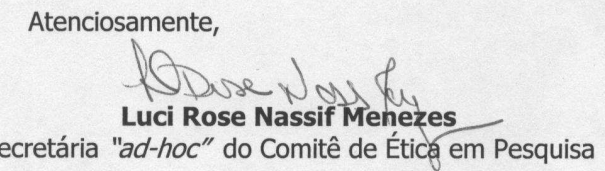

Ilma. Sra.

Profa. Dra. ROSSANA PEREIRA DE ALMEIDA ANTUNES

Professora Associada do Departamento de Materiais Dentários e Prótese - FORP/USP 